\title{
Height-diameter allometry of tropical forest trees
}

T. R. Feldpausch ${ }^{1, *}$, L. Banin ${ }^{1, *}$, O. L. Phillips ${ }^{1}$, T. R. Baker ${ }^{1}$, S. L. Lewis ${ }^{1}$, C. A. Quesada ${ }^{1,2}$, K. Affum-Baffoe ${ }^{3}$, E. J. M. M. Arets ${ }^{4,5}$, N. J. Berry ${ }^{1, * *}$, M. Bird ${ }^{6, * *}$, E. S. Brondizio ${ }^{7}$, P. de Camargo ${ }^{8}$, J. Chave ${ }^{9}$, G. Djagbletey ${ }^{10}$, T. F. Domingues ${ }^{11, * * * *}$, M. Drescher ${ }^{5,12}$, P. M. Fearnside ${ }^{2}$, M. B. França ${ }^{2}$, N. M. Fyllas ${ }^{1}$, G. Lopez-Gonzalez ${ }^{1}$, A. Hladik ${ }^{13}$, N. Higuchi ${ }^{2}$, M. O. Hunter ${ }^{14}$, Y. Iida ${ }^{15}$, K. A. Salim ${ }^{16}$, A. R. Kassim ${ }^{17}$, M. Keller ${ }^{14,18}$, J. Kemp ${ }^{19}$, D. A. King ${ }^{20}$, J. C. Lovett $^{21}$, B. S. Marimon ${ }^{22}$, B. H. Marimon-Junior ${ }^{22}$, E. Lenza ${ }^{22}$, A. R. Marshall ${ }^{23}$, D. J. Metcalfe ${ }^{24}$, E. T. A. Mitchard ${ }^{11}$, E. F. Moran ${ }^{7}$, B. W. Nelson ${ }^{2}$, R. Nilus ${ }^{25}$, E. M. Nogueira ${ }^{2}$, M. Palace ${ }^{14}$, S. Patiño $^{1,26}$, K. S.-H. Peh ${ }^{1, * * * *}$, M. T. Raventos ${ }^{* * *}$, J. M. Reitsma ${ }^{27}$, G. Saiz ${ }^{6 * * *}$, F. Schrodt ${ }^{1}$, B. Sonké ${ }^{28}$, H. E. Taedoumg ${ }^{28}$, S. Tan ${ }^{29}$, L. White ${ }^{30, * * * * *}$, H. Wöll ${ }^{31}$, and J. Lloyd ${ }^{1, * * *}$

${ }^{1}$ Earth and Biosphere Institute, School of Geography, University of Leeds, Leeds, LS2 9JT, UK

${ }^{2}$ Instituto Nacional de Pesquisas da Amazonia (INPA), Manaus, Brazil

${ }^{3}$ Forestry Commission of Ghana, P.O. Box 1457, Kumasi, Ghana

${ }^{4}$ Centre for Ecosystem Studies, Alterra, Wageningen Univ. and Research Centre, 6700 AA, Wageningen, The Netherlands

${ }^{5}$ Programa de Manejo de Bosques de la Amazonia Boliviana (PROMAB), P.O. Box 107, Riberalta, Bolivia

${ }^{6}$ School of Geography and Geosciences, Univ. of St. Andrews, KY16 9AL, UK

${ }^{7}$ Department of Anthropology and the Anthropological Center for Training and Research on Global Environmental Change, Indiana University, Bloomington, USA

${ }^{8}$ Centro de Energia Nuclear na Agricultura, Av. Centenãrio, 303 CEP: 13400-970, Piracicaba, São Paulo, Brazil

${ }^{9}$ Universite Paul Sabatier/CNRS, Laboratoire EDB UMR 5174, batiment 4R3, 31062 Toulouse, France

${ }^{10}$ Forest Research Institute of Ghana (FORIG), Kumasi, Ghana

${ }^{11}$ School of GeoSciences, University of Edinburgh, Drummond St, Edinburgh, EH8 9XP, UK

${ }^{12}$ School of Planning, University of Waterloo, 200 University Avenue West, Waterloo, ON N2L 3G1, Canada

${ }^{13}$ Eco-anthropologie et Ethnobiologie, D'epartement Hommes, Natures, Soci'et'es, MNHN, 4, avenue du Petit Château 91800 Brunoy, France

${ }^{14}$ Complex Systems Research Center, Univ. of New Hampshire, Durham, NH, 03824, USA

${ }^{15}$ Graduate School of Environmental Science, Hokkaido University, Sapporo, 060-0810, Japan

${ }^{16}$ Kuala Belalong Field Studies Centre, Universiti Brunei Darussalam, Biology Department, Jalan Tungku Link, BE1410, Brunei Darussalam

${ }^{17}$ Forest Research Institute Malaysia (FRIM), 52109 Kepong, Selangor Darul Ehsan, Malaysia

${ }^{18}$ Int. Institute of Tropical Forestry, USDA Forest Service, San Juan, 00926, Puerto Rico

${ }^{19}$ Queensland Herbarium, Department of Environment and Resource Management, Townsville QLD 4810, Australia

${ }^{20}$ Biological and Ecological Engineering, Oregon State University, Corvallis, OR 97331, USA

${ }^{21}$ CSTM - Twente Centre for Studies in Technology and Sustainable Development, University of Twente; Postbus 217;

7500 AE; Enschede, The Netherlands

${ }^{22}$ Universidade do Estado de Mato Grosso, Caixa Postal 08, CEP 78690-000, Nova Xavantina, MT, Brazil

${ }^{23}$ CIRCLE, Environment Department, University of York, UK, and Flamingo Land, North Yorkshire, UK

${ }^{24}$ CSIRO Ecosystem Sciences, Tropical Forest Research Centre, Atherton, QLD 4883, Australia

${ }^{25}$ Forest Research Centre, Sabah Forestry Department, Sandakan, 90715, Malaysia

${ }^{26}$ Universidad Nacional de Colombia sede Amazonia, Km 2 vía Tarapacá, Leticia, Amazonas, Colombia

${ }^{27}$ Bureau Waardenburg bv, P.O. Box 365, 4100 AJ Culemborg, The Netherlands

${ }^{28}$ Plant Systematic and Ecology Laboratory, Department of Biology, Higher Teachers Training College, University of Yaounde I, P.O. Box 047 Yaounde Cameroon

Correspondence to:

T. R. Feldpausch (t.r.feldpausch@leeds.ac.uk)

L. Banin (lindsay.banin@gmail.com)

Published by Copernicus Publications on behalf of the European Geosciences Union. 


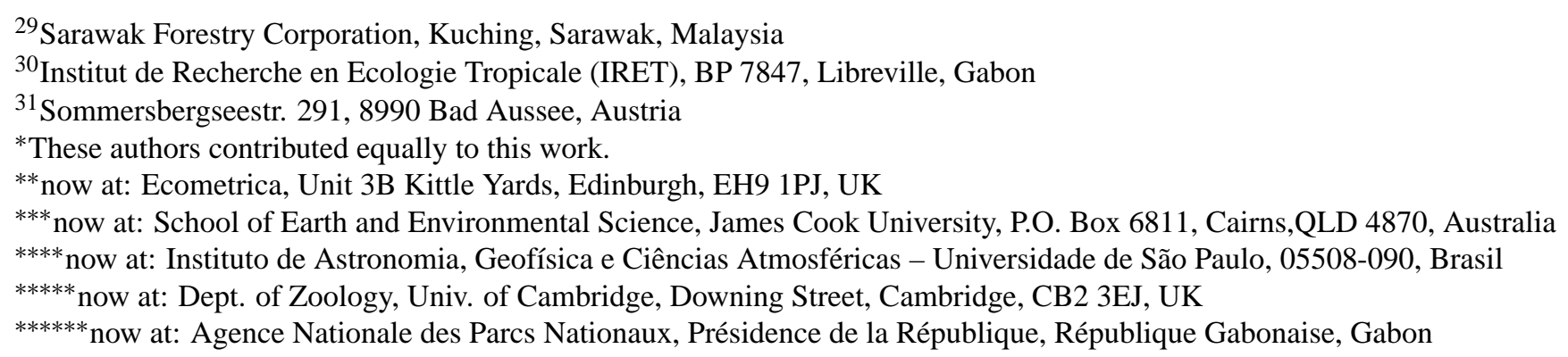

Received: 13 September 2010 - Published in Biogeosciences Discuss.: 25 October 2010

Revised: 11 March 2011 - Accepted: 21 March 2011 - Published: 5 May 2011

\begin{abstract}
Tropical tree height-diameter $(H: D)$ relationships may vary by forest type and region making large-scale estimates of above-ground biomass subject to bias if they ignore these differences in stem allometry. We have therefore developed a new global tropical forest database consisting of 39955 concurrent $H$ and $D$ measurements encompassing 283 sites in 22 tropical countries. Utilising this database, our objectives were:
\end{abstract}

1. to determine if $H: D$ relationships differ by geographic region and forest type (wet to dry forests, including zones of tension where forest and savanna overlap).

2. to ascertain if the $H: D$ relationship is modulated by climate and/or forest structural characteristics (e.g. standlevel basal area, $A$ ).

3. to develop $H: D$ allometric equations and evaluate biases to reduce error in future local-to-global estimates of tropical forest biomass.

Annual precipitation coefficient of variation $\left(P_{\mathrm{V}}\right)$, dry season length $\left(S_{\mathrm{D}}\right)$, and mean annual air temperature $\left(T_{\mathrm{A}}\right)$ emerged as key drivers of variation in $H: D$ relationships at the pantropical and region scales. Vegetation structure also played a role with trees in forests of a high $A$ being, on average, taller at any given $D$. After the effects of environment and forest structure are taken into account, two main regional groups can be identified. Forests in Asia, Africa and the Guyana Shield all have, on average, similar $H: D$ relationships, but with trees in the forests of much of the Amazon Basin and tropical Australia typically being shorter at any given $D$ than their counterparts elsewhere.

The region-environment-structure model with the lowest Akaike's information criterion and lowest deviation estimated stand-level $H$ across all plots to within a median -2.7 to $0.9 \%$ of the true value. Some of the plot-to-plot variability in $H: D$ relationships not accounted for by this model could be attributed to variations in soil physical conditions. Other things being equal, trees tend to be more slender in the absence of soil physical constraints, especially at smaller $D$. Pantropical and continental-level models provided less robust estimates of $H$, especially when the roles of climate and stand structure in modulating $H: D$ allometry were not simultaneously taken into account.

\section{Introduction}

High rates of vertical growth allow trees to physically dominate over other plant growth forms where the environment is suitable (Moles et al., 2009). Ecological studies concerned with horizontal components of forest structure, such as stem density and basal area, have shown large scale variations along broad environmental and/or edaphic gradients (Proctor et al., 1983; Baker et al., 2004b; Malhi et al., 2006; Paoli et al., 2008); however, variations in the vertical components of forest structure and their causes remain much less studied. This is despite available evidence suggesting that tree height, $H$, for a given diameter $(D)$ may vary significantly among species (King, 1996) and across regions (Nogueira et al., 2008b). Such differences could hold important implications for carbon storage potential of tropical forests. This is because tropical tree above-ground biomass and carbon fluxes are usually estimated by applying allometric equations to diameter measurements only: thus assuming a constant height-diameter $(H: D)$ ratio, stem taper and crown mass fraction (e.g., Baker et al., 2004a; Chave et al., 2005; Phillips et al., 1998; Malhi et al., 2006). But if tropical tree $H: D$ allometries vary significantly and systematically, then this assumption could be introducing systematic errors to large-scale biomass estimates. Recent estimates of the impact of changing tropical forest biomass and productivity on the global carbon cycle (Phillips et al., 2008; Lewis et al., 2009; Phillips et al., 2009) are sensitive to the underlying assumptions of the allometric models that scale tree measurements to carbon 
numbers. Here, we analyse a new, global, wet to dry tropical forest tree height-diameter database of nearly forty thousand individual tree height measurements. Our aim is to improve understanding of tropical tree allometric differences and reduce uncertainty in tropical biomass carbon estimates at the regional, continental and global scale.

We considered it likely that tropical tree $H: D$ allometry would be found to vary substantially along spatial and environmental gradients. For example, altitudinal transects have shown that stand-level average $H$ declines more sharply with elevation than does the average $D$ (Grubb, 1977), with the latter sometimes even increasing with altitude (Lieberman et al., 1996). Soil substrate may also interact with altitude to modulate $H: D$ relationships (Aiba and Kitayama, 1999). Independent of altitude, plot-to-plot variability has also been observed. For example, Ketterings (2001) suggested that site-specific $H: D$ relationships were required for accurate biomass estimates of mixed secondary forests in Indonesia.

There are also indications that climatic regime can influence $H: D$ allometry. Hydraulic limitation theory predicts that tree height is ultimately limited by water availability, and thus gradients in maximum tree height may be expected to coincide with rainfall distribution (Ryan and Yoder, 1997; Ryan et al., 2006). But as water becomes more limiting, there are no associated reasons for $D$ to be similarly reduced. Indeed, a greater sapwood cross sectional area per unit height may well be advantageous in water limited environments in terms of water transport efficiency. Bullock (2000) observed trees in a very dry deciduous forest in Mexico to be exceptionally "thick" for a given height, with a logarithmic $H: D$ allometric scaling coefficient much smaller than those reported for wetter forests.

Forest structure, e.g. stem density, may also affect individual tree $H: D$ allometry and mono-specific plantation spacing experiments have been used to demonstrate these effects. For example, working with Cordia alliodora in Costa Rica, Hummel (2000) found that trees that were more widely spaced tended to have similar $H$ but a greater $D$ than those that were more closely packed. These differences may be associated with either the increased competition for light or the reduced wind stress in more densely packed stands (Henry and Aarssen, 1999). It would also be expected that trees growing in regions characterized by occasional but extreme wind events such as cyclones or hurricanes would also tend be shorter for a given $D$ than those growing in less perturbed environments due to a need to withstand windthrow events (de Gouvenain and Silander, 2003).

Despite the above considerations, most estimates of tropical forest stand-level biomass and/or productivity have been based on measurements of tree diameters alone or a combination of diameter and wood density, $\rho_{\mathrm{W}}$ (Baker et al., 2004b; Chambers et al., 2001; Malhi et al., 2004, 2006; Nascimento and Laurance, 2002). Equations to improve biomass estimates by including tree height as an additional factor do, however, exist (Brown et al., 1989; Chave et al., 2005) and analysis of such equations has shown that tree height helps explain a significant further amount of variation in aboveground biomass. For example, as shown by the pantropical equations of Chave et al. (2005), the most important parameters in estimating biomass (in decreasing order of importance) were $D, \rho_{\mathrm{W}}, H$ and forest type (classified as dry, moist or wet forest) with the inclusion of $H$ reported to reduce the standard error of biomass estimates from 19.5 to $12.5 \%$ (Chave et al., 2005). Similarly, differences in $H$ alone led to reductions in biomass estimates of between 4 and $11 \%$ in Southern Amazonian forests (dominated by shorter trees) as compared to using an uncorrected biomass model developed in Central Amazonia (Nogueira et al., 2008b).

In practice, height is rarely included as a parameter in above-ground biomass calculations (but see Lewis et al., 2009). This omission of tree height in tropical forest biomass estimates has resulted, at least in part, from of a lack of applicable equations to estimate tree $H$ from $D$. Although many site specific equations exist, and with some more general analyses having been undertaken, especially in conjunction with the rapidly proliferating literature on size dependent constraints on productivity and underlying "optimality theory" (e.g., Niklas and Spatz, 2004), to our knowledge we are currently limited to one pantropical moist forest $H: D$ allometric equation derived from a dataset of ca. 4000 trees sampled in Venezuela, Puerto Rico and Papua New Guinea (Brown et al., 1989). Improved understanding of variation in $H: D$ relationships within and across the major tropical forest regions should contribute to the development of more accurate models for biomass estimation.

To address the above questions, this study examines allometric differences for trees in 283 tropical forest sample plots spanning a broad range of climatic conditions, with data from all major tropical forest regions of the world. Our objectives were to:

1. determine if tree $H: D$ relationships differ with geographic location;

2. ascertain the extent to which geographical differences in $H: D$ relationships result from site, climate and/or forest structural characteristics; and,

3. develop $H: D$ allometric equations and evaluate their biases to reduce error in local and pantropical forest biomass estimates.

\section{Materials and methods}

We present a compilation of published and unpublished measurements of tropical tree height and forest structure from 283 plots generally ranging in size from 0.22 to 1 ha, with two large plots of ca. 50 ha, consisting of 39955 individual tree height measurements with concomitant measurement 


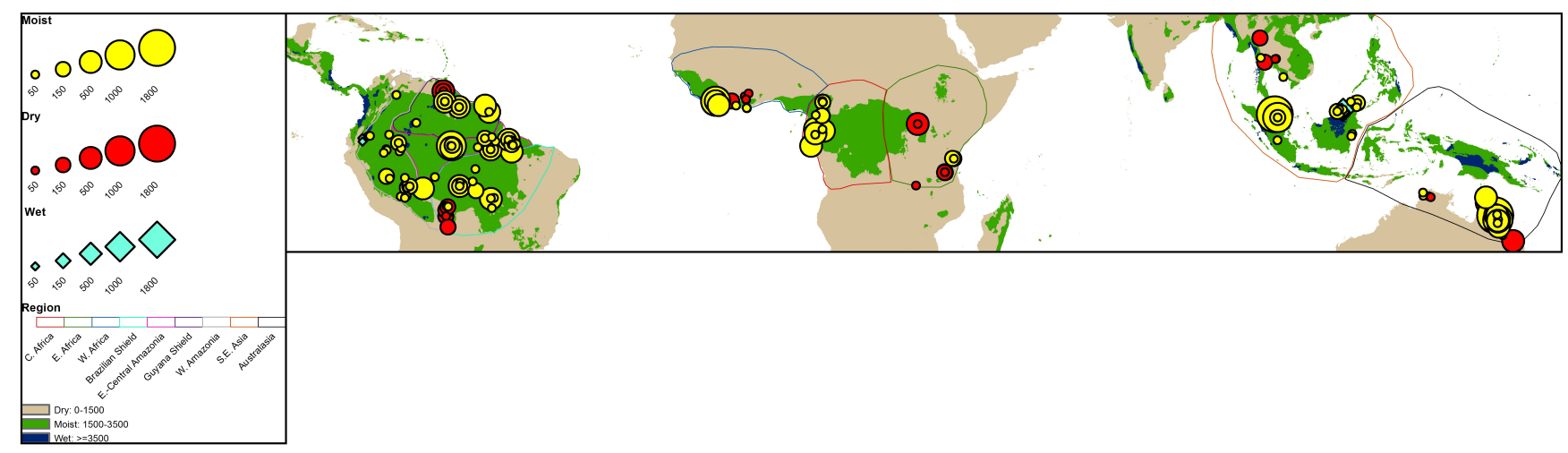

Fig. 1. Location of study sites. Symbols are proportional to plot sample sizes for tree height measurements. See Supplement, Table S1 for plot details.

of diameter at breast height $(1.3 \mathrm{~m}) \geq 1 \mathrm{dm}$ (Fig. 1, Supplement, Table S1). In most cases permanent sample plots had been established, with tree height measured primary in oldgrowth $(n=36386)$ and some secondary $(n=3569)$ forest with stand-level tree basal area $\left(A, \mathrm{~m}^{2} \mathrm{ha}^{-1}\right)$ and stem density typically measured non-destructively using standardized international inventory methods (e.g., Phillips et al., 2010). In brief, all live trees and palms with stems greater than $1 \mathrm{dm}$ diameter at breast height were measured to the nearest $1 \mathrm{~mm}$ at $1.3 \mathrm{~m}$ height or $0.5 \mathrm{~m}$ above deformations, buttresses or stilt-roots, where the stem became uniform. Trees had usually been identified to species by a local botanist. The vegetation sampled spanned a wide range of stem diameters, stem densities and basal areas (Table 1), with $A$ ranging from 5.7 to $7.1 \mathrm{~m}^{2} \mathrm{ha}^{-1}$ in semi-deciduous old-growth forests in South America and Australia, to a maximum of $65.7 \mathrm{~m}^{2} \mathrm{ha}^{-1}$ in old-growth forests in Australia.

\subsection{Study locations and climate}

Measurements were made in 22 countries in geographically distinct regions (e.g., Brazilian versus Guyana Shield) in Africa, Asia, Australia and South America. Climate data (mean annual precipitation, $P_{\mathrm{A}}$, precipitation coefficient of variation, $P_{\mathrm{V}}$, dry season length, $S_{\mathrm{D}}$, and mean annual temperature, $T_{\mathrm{A}}$ ) and altitude were obtained from WorldClim global coverage at a $2.5 \mathrm{~min}$ resolution based on meteorological station data from 1950-2000 (Hijmans et al., 2005). We defined $S_{\mathrm{D}}$ as the total months per year with $<0.10 \mathrm{~m}$ precipitation (this monthly rate being roughly equivalent to the typical transpiration rate of a tropical forest in the absence of water limitations: Shuttleworth, 1988; Malhi and Wright, 2004). The $P_{\mathrm{V}}$ is calculated as $\sigma / \mu$ where $\mu$ is the mean and $\sigma$ the standard deviation on the mean monthly precipitation values for each site. As detailed below, data utilised for this analysis consist mostly of previously unreported measurements with much of the new data from Africa being made available through the AfriTRON network (Lewis et al., 2009), previously reported and new height data from South America through the RAINFOR network (Baker et al., 2009; Lloyd et al., 2010) and with substantial new contributions for Asia (Banin, 2010).

\subsubsection{Africa}

Three geographic regions were identified, viz. West, Central and East Africa with a total of 11801 trees measured. West African measurements were made in Ghana and Liberia, along with previously published data (Müller and Nielsen, 1965), sampled across $P_{\mathrm{A}}$ varying from 1.21 to $2.38 \mathrm{~m} \mathrm{a}^{-1}$ (Table 1). Central African sites comprise plots sampled in Southern Cameroon and Gabon. These sites represent a $P_{\mathrm{A}}$ ranging from $1.59 \mathrm{~m} \mathrm{a}^{-1}$ in the north to $1.83 \mathrm{~m} \mathrm{a}^{-1}$ in the south. East African sites had been established in Uganda and Tanzania, with $P_{\mathrm{A}}$ ranging from 1.20 to $1.87 \mathrm{~m} \mathrm{a}^{-1}$. Precipitation is seasonal at all African sites, with $P_{\mathrm{V}}$ varying from 0.40 to 0.93 . The number of months with precipitation less than $0.1 \mathrm{~m}$ per month varies from 1 to 8 months across the African sites (Table 1).

\subsubsection{South America}

Plots from South America were classified into four regions based on geography and substrate origin. These consisted of Western Amazonia (Ecuador, Peru and Colombia), with soils mostly originating from recently weathered Andean deposits (Quesada et al., 2009b), the Southern Amazonian area of the Brazilian Shield (Bolivia and Brazil), the Guyana Shield (Guyana, French Guiana, Venezuela), and EasternCentral Amazonia (Brazil) comprised of old sedimentary substrates derived from the other three regions. Tree height was measured for a total of 17067 trees in South America. Western Amazonian sites incorporated moist and wet forests with $P_{\mathrm{A}}$ from 1.66 to $3.87 \mathrm{~m} \mathrm{a}^{-1}$. In the Brazilian Shield, forests included the chiquitano (dry forest) and dry and moist forests of Bolivia and Brazil with $P_{\mathrm{A}}$ from 0.82 
Table 1. Environmental and forest structure variables tested in models, including minimum, maximum, median, mean \pm StDev, basal area $\left(A, \mathrm{~m}^{2} \mathrm{ha}^{-1}\right)$, tree stem density $\left(D_{\mathrm{S}}, \mathrm{ha}^{-1}\right)$ mean annual precipitation $\left(P_{\mathrm{A}}, \mathrm{m} \mathrm{a}^{-1}\right)$ precipitation coefficient of variance $\left(P_{\mathrm{V}}\right)$, mean annual temperature $\left(T_{\mathrm{A}}\right)$, dry season $\left(S_{\mathrm{D}}\right.$, no. months $\left.<0.1 \mathrm{~m}\right)$, altitude $\left(A_{\mathrm{L}}, \mathrm{m}\right.$ a.s.1.) for primary and secondary forests in Africa, Asia, Australia and South America.

\begin{tabular}{|c|c|c|c|c|c|c|c|c|c|c|}
\hline & C. Africa & E. Africa & W. Africa & Brazilian Shield & E.C. Amazonia & Guyana Shield & W. Amazonia & SE. Asia & Australia & Grand Mean \\
\hline \multicolumn{11}{|l|}{$A\left(\mathrm{~m}^{2} \mathrm{ha}^{-1}\right)$} \\
\hline Min/Max & $11.9 / 42.9$ & $17 / 53.7$ & $22.6 / 34.6$ & $7.1 / 32.4$ & $1.7 / 47.7$ & $16 / 37$ & $15.6 / 39$ & $11.2 / 52$ & $5.7 / 65.7$ & $1.7 / 65.7$ \\
\hline Median & 35.8 & 33.9 & 27.4 & 20.4 & 25.0 & 27.7 & 29.0 & 34.4 & 54.3 & 29.2 \\
\hline Mean \pm StDev & $33.4 \pm 7.5$ & $34 \pm 8.6$ & $27.8 \pm 2.5$ & $22.2 \pm 5.3$ & $23.5 \pm 10.2$ & $27.6 \pm 5.4$ & $27.8 \pm 2.9$ & $32.2 \pm 8.0$ & $50.2 \pm 12.2$ & $32.4 \pm 12.6$ \\
\hline \multicolumn{11}{|l|}{$D_{\mathrm{S}}\left(\mathrm{ha}^{-1}\right)$} \\
\hline Min/Max & $286 / 1056$ & $230 / 639$ & $126 / 608$ & $236 / 828$ & $153 / 927$ & $297 / 992$ & $278 / 814$ & NA & $340 / 1153$ & $126 / 1153$ \\
\hline Median & 429 & 453 & 413 & 539 & 608 & 511 & 530 & NA & 885 & 530 \\
\hline Mean \pm StDev & $451 \pm 98$ & $462 \pm 105$ & $414 \pm 75$ & $551 \pm 110$ & $595 \pm 173$ & $515 \pm 99$ & $559 \pm 74$ & NA & $871 \pm 181$ & $586 \pm 204$ \\
\hline \multicolumn{11}{|l|}{$P_{\mathrm{A}}\left(\mathrm{m} \mathrm{a}^{-1}\right)$} \\
\hline Min/Max & $1.59 / 1.83$ & $1.12 / 1.87$ & $1.21 / 2.38$ & $0.82 / 2.36$ & $1.78 / 2.64$ & $1.38 / 3.42$ & $1.66 / 3.86$ & $1.09 / 3.80$ & $0.67 / 2.84$ & $0.67 / 3.86$ \\
\hline Median & 1.66 & 1.38 & 2.33 & 1.64 & 2.21 & 2.64 & 1911 & 2.67 & 1.67 & 1.96 \\
\hline Mean \pm StDev & $1.70 \pm 0.72$ & $1.43 \pm 0.15$ & $2.20 \pm 0.22$ & $1.67 \pm 0.27$ & $2.16 \pm 0.29$ & $2.73 \pm 0.49$ & $2.23 \pm 0.64$ & $2.45 \pm 0.66$ & $1.78 \pm 0.45$ & $2.08 \pm 0.54$ \\
\hline \multicolumn{11}{|l|}{$P_{\mathrm{V}}$} \\
\hline Min/Max & $0.57 / 0.75$ & $0.42 / 0.89$ & $0.40 / 0.93$ & $0.56 / 0.81$ & $0.33 / 0.85$ & $0.24 / 0.47$ & $0.15 / 0.66$ & $0.14 / 0.86$ & $0.72 / 1.11$ & $0.15 / 1.11$ \\
\hline Median & 0.65 & 0.70 & 0.40 & 0.75 & 0.63 & 0.44 & 0.55 & 0.30 & 0.86 & 0.59 \\
\hline Mean \pm StDev & $0.66 \pm 0.06$ & $0.69 \pm 0.20$ & $0.46 \pm 0.1$ & $0.75 \pm 0.06$ & $0.61 \pm 0.13$ & $0.42 \pm 0.06$ & $0.48 \pm 0.20$ & $0.32 \pm 0.17$ & $0.85 \pm 0.09$ & $0.60 \pm 0.21$ \\
\hline \multicolumn{11}{|l|}{$T_{\mathrm{A}}\left({ }^{\circ} \mathrm{C}\right)$} \\
\hline Min/Max & $23.3 / 25.4$ & $15.3 / 24.9$ & $25.7 / 26.7$ & $21.5 / 26.1$ & $25.7 / 27.1$ & $25.1 / 26.6$ & $23.7 / 26.5$ & $15.5 / 27.5$ & $18.4 / 25.7$ & $15.3 / 27.5$ \\
\hline Median & 23.7 & 20.9 & 25.9 & 25.0 & 26.8 & 26.6 & 26.3 & 26.4 & 22.3 & 25.7 \\
\hline Mean \pm StDev & $24.0 \pm 0.7$ & $21.2 \pm 2.0$ & $26.0 \pm 0.2$ & $24.7 \pm 0.6$ & $26.5 \pm 0.6$ & $26 \pm 0.7$ & $25.9 \pm 0.8$ & $26.0 \pm 1.5$ & $21.8 \pm 1.7$ & $24.7 \pm 2.2$ \\
\hline \multicolumn{11}{|l|}{$S_{\mathrm{D}}$ (months) } \\
\hline Min/Max & $4 / 5$ & $3 / 8$ & $1 / 6$ & $3 / 9$ & $1 / 6$ & $0 / 4$ & $0 / 5$ & $0 / 6$ & $4 / 10$ & $0 / 10$ \\
\hline Median & 4 & 6 & 1 & 5 & 5 & 1 & 4 & 0 & 7 & 4.0 \\
\hline Mean \pm StDev & $4.2 \pm 0.4$ & $5.7 \pm 1.5$ & $1.7 \pm 1.1$ & $5.2 \pm 0.9$ & $4.4 \pm 1.6$ & $1.4 \pm 0.9$ & $3.1 \pm 2.2$ & $0.5 \pm 1.7$ & $6.4 \pm 1.1$ & $3.7 \pm 2.4$ \\
\hline \multicolumn{11}{|l|}{$A_{\mathrm{L}}(\mathrm{m}$ a.s.l) } \\
\hline Min/Max & $236 / 858$ & $281 / 1779$ & $11 / 327$ & $83 / 731$ & $9 / 256$ & $90 / 407$ & $98 / 511$ & $14 / 2178$ & $14 / 1054$ & $9 / 2178$ \\
\hline Median & 597 & 1066 & 159 & 341 & 102 & 90 & 172 & 135 & 812 & 213 \\
\hline Mean \pm St Dev & $529 \pm 195$ & $1094 \pm 260$ & $187 \pm 52$ & $338 \pm 72$ & $100 \pm 80$ & $143 \pm 95$ & $197 \pm 77$ & $211 \pm 276$ & $669 \pm 346$ & $347 \pm 328$ \\
\hline
\end{tabular}

to $2.36 \mathrm{~m} \mathrm{a}^{-1}$. Vegetation formations in the Guyana Shield included dry and moist forests with $P_{\mathrm{A}}$ ranging from 1.35 to $3.42 \mathrm{~m} \mathrm{a}^{-1}$. Eastern-Central Amazonian sites included dry and moist forest in the Brazilian states of Amazonas and Pará with $P_{\mathrm{A}}$ ranging from 1.78 to $2.64 \mathrm{~m} \mathrm{a}^{-1}$. The $P_{\mathrm{V}}$ ranged from 0.15 to 0.85 across all South American sites and $S_{\mathrm{D}}$ ranged from 0 to 9 months (Table 1 ).

\subsubsection{Asia}

We classified forests in Asia as a single region for this study because of small sample size, with a total of 2616 trees sampled. Wet and moist forests were sampled in Sarawak, Sabah and Brunei (making up Northern Borneo), Kalimantan (Indonesian Borneo) and Peninsular Malaysia, and data from dry forests were compiled from the literature for Cambodia and Thailand (Yamakura et al., 1986; Aiba and Kitayama, 1999; Hozumi et al., 1969; Ogawa et al., 1965; Sabhasri et al., 1968; Neal, 1967; Ogino et al., 1967). Precipitation ranged from 1.09 to $3.80 \mathrm{ma}^{-1}$, with $S_{\mathrm{D}}$ between 0 and 6 months and $P_{\mathrm{V}}$ varying from 0.14 to 0.86 (Table 1).

\subsubsection{Australia}

Australian measurements were taken in tropical "dry scrub" and moist forest in Northern Australia, which taken together with published data (Graham, 2006) provided measurements for a total of 8471 trees. All trees sampled were from Northern Queensland where precipitation varies over very short distance from coastal to inland sites, with $P_{\mathrm{A}}$ ranging from 0.67 to $2.84 \mathrm{~m} \mathrm{a}^{-1}, S_{\mathrm{D}}$ ranging from 4 to 10 months and with high $P_{\mathrm{V}}$ between 0.72 to 1.11 . Although at an unusually low rainfall for what is generally considered tropical forest, nearly $90 \%$ of the species within the "scrub forests" of inland Australia are also found in the more typical dry tropical forests which occur at much higher precipitation regimes closer to the Queensland coast (Fensham, 1996) and have thus been included in the current study (see also Sect. 2.4).

\subsection{Tree height and diameter}

Tree height $(H)$ was measured for a subset of trees or every tree $\geq 1 \mathrm{dm}$ in diameter in each plot. A minimum size of $1 \mathrm{dm}$ was selected since it is a frequently selected cut-off point in forest inventory measurements, and is therefore suitable in terms of application to biomass estimation. When 
a subset of trees was sampled, $H$ was generally measured by stratified $1 \mathrm{dm}$ diameter classes to aid in the development of plot-specific $H: D$ curves, with a minimum of 10 individuals randomly selected from each diameter class (i.e., 1 to $2,>2$ to $3,>3$ to $4 \mathrm{dm}$, and $>4 \mathrm{dm}$ ) (sampling methods are detailed further in Table S1). Tree heights had been measured with Vertex hypsometers (Vertex Laser VL400 Ultrasonic-Laser Hypsometer III, Haglöf Sweden), laser range-finders (e.g., LaserAce 300 and LaserAce Hypsometer; MDL), mechanical clinometers, physically climbing the tree with a tape measure, or by destructive means (detailed by site in Table S1). To examine how tree $H$ was related to stem $D$, independent of external factors such as recent damage by treefall, we exluded from the analysis all trees known to be broken or with substantial crown damage and all palms. Tree architectural differences were first evaluated by continent and region using the Kruskal-Wallis non-parametric multiple comparison test from the pgirmess package (Giraudoux, 2010) in " $R$ " (R Development Core Team, 2009).

\subsection{Soil chemical and physical characteristics}

Soil physical and chemical properties had also been sampled in a subset of plots in South America, Africa, Asia and Australia using standard protocols (Quesada et al., 2010). Briefly, a minimum of five samples were taken in each plot up to $2 \mathrm{~m}$ depth (substrate permitting), a soil pit dug to $2 \mathrm{~m}$ depth and soil sampled an additional $2 \mathrm{~m}$ depth from the base of the pit. Exchangeable cations were determined by the silver thiourea method (Pleysier and Juo, 1980), soil carbon in an automated elemental analyser as described by Pella (1990) and Nelson and Sommers (1996), and particle size analysed using the Boyoucos method (Gee and Bauder, 1986). An index of soil physical properties was calculated for each site (Quesada et al., 2010). This "Quesada Index", П, is based on measures of effective soil depth, soil structure, topography and anoxia.

\subsection{Classification of vegetation types}

Classifying forests according to environmental factors (e.g. precipitation) and forest structure (e.g. basal area, stem density) has in the past been found useful in segregating vegetation to apply appropriate allometric equations (e.g., Brown et al., 1989). To explore the success of simplified allometric equations (which do not require the input of multiple environmental parameters) we classified vegetation based on forest life zones (sensu Chave et al., 2005) forests being classed as dry $\left(P_{\mathrm{A}}<1.5 \mathrm{~m}\right)$, moist $\left(1.5 \mathrm{~m} \leq P_{\mathrm{A}} \leq 3.5 \mathrm{~m}\right)$ or wet $\left(P_{\mathrm{A}}>3.5 \mathrm{~m}\right)$ (Table 1, Fig. S1). We distinguished transitional forest from savanna as vegetation formations that do not normally support a grass-dominated understory (i.e. canopy closure). Successional status was assigned as either old-growth or secondary forest.

\subsection{Model development and evaluation}

A number of allometric models describing the relationship between $H$ and $D$ have been described in the past taking many linear and non-linear forms (e.g., Fang and Bailey, 1998). For this study we initially tested equations of five forms: $\log$-linear, $\log -\log$, Weibull, monomolecular, and rectangular hyperbola (see Supplement, Table S2). Loglinear and $\log -\log$ are the most frequently used (e.g., Brown et al., 1989) and have been suggested as the most parsimonious models (Nogueira et al., 2008a). On the other hand, asymptotic functions have been argued to be useful for comparisons between forests since a maximum height parameter is fitted using iterative non-linear regression (Bailey, 1980). These functions relate $H$ to $D$ at $1.3 \mathrm{~m}$, with maximum height, $H_{\max }$ being one important parameter in the associated model fit.

In order to inform our choice of model, we first compared the ability of the five allometric functions to predict $H$ at multiple scales (pantropical, continental, regional and plot). To fit these alternative models, we used the "nlme" package (Pinheiro et al., 2010) in the R software with associated parameters estimated as forest- or region-specific constants (Supplement, Table S3). Plot-level models (with individual parameters for each plot) did not consistently explain a greater percent of the variability in the data compared to that of more aggregated large-scale models. A comparison of the deviation of models of different forms is shown in the Supplement, Table S4, Fig. S2.

Irrespective of geographic scale, models of the log-log form had the lowest deviation from measured values, with the residuals of tree $H$ not showing any detectable trend by diameter class when the log-log relationship was applied (Fig. S3). In the case of this dataset, asymptotic functions such as the Weibull form, which may provide an estimate of ecologically meaningful $H_{\max }$, provided poorer estimates of $H$ relative to the $\log -\log$ models for dry and wet, but not for moist forests. The greatest constraint on non-linear models was that they frequently did not converge (e.g., $30 \%$ of the time for the Weibull function for plot-level fits).

Based on the above analysis, we therefore chose the $\log (H) \propto \log (D)$ parameterisation for a more detailed study of the effects of location, stand structure and environment on tree $H: D$ relationships.

\subsubsection{The multi-level log-log model}

Using multilevel modeling techniques (Snijders and Bosker, 1999), we first considered the relationship between $H$ and $D$ independent of how the $H: D$ relationship may vary across spatial units (continent, region and plot) and treated both tree-to-tree variation (within a plot) and variations in overall mean coefficients as random (residual) effects. 
Considering tree-to-tree variation as the only source of "residual" error, the global average $H: D$ relationship can be defined as

$$
\log \left(H_{\mathrm{tp}}\right)=\beta_{0 \mathrm{p}}+\beta_{1} \log \left(D_{\mathrm{tp}}\right)+R_{\mathrm{tp}},
$$

where $H_{\text {tp }}$ is the tree height (measured on tree "t" located within plot "p"), $\beta_{0 \mathrm{p}}$ is an intercept term which, as indicated by its nomenclature, can vary between plots, $\beta_{1}$ is the slope of the regression between the log-transformed $H$ and $D$ (common to all trees and plots) and $R_{\mathrm{tp}}$ is the residual. With $\beta_{0 \mathrm{p}}$ taken as common to all plots, Eq. (1) then transforms to a simple $\log -\log$ regression equation. Although in most cases the residual term is not specifically written. Taking the fitted (fixed) effects only then

$e^{\log \left(H_{\mathrm{tp}}\right)}=e^{\beta_{0 \mathrm{p}}+\beta_{1} \log \left(D_{\mathrm{tp}}\right)}$,

which simplifies to

$H_{\mathrm{tp}}=e^{\beta_{0 \mathrm{p}}} D_{\mathrm{tp}}{ }^{\beta_{\mathrm{tp}}}$.

Thus, in any log-log model fit which follows, the intercept term can be taken to represent the (natural) logarithm of the value of $H_{\mathrm{tp}}$ when $D_{\mathrm{tp}}=1 \mathrm{dm}$ with the slope representing a "scaling coefficient", i.e. the proportional change in $H_{\mathrm{tp}}$ for any given change in $D_{\mathrm{tp}}$.

The intercept term of Eq. (1) can be split into an average intercept and plot dependent deviations. Firstly we write

$\beta_{0 \mathrm{p}}=\gamma_{00}+U_{0 \mathrm{p}}$,

where $\gamma_{00}$ is the average intercept for the trees sampled and $U_{0 \mathrm{p}}$ is a random variable controlling for the effects of variations between plots (i.e. with a unique value for each plot). Then, using a general notation, we can combine Eqs. (1) and (4) to yield

$\log \left(H_{\mathrm{tp}}\right)=\gamma_{00}+\beta_{1} \log \left(D_{\mathrm{tp}}\right)+U_{0 \mathrm{p}}+R_{\mathrm{tp}}$

where $\beta_{1}$ describes how $H$ varies with the natural logarithm of $D$ but with the same value for all trees within all plots. Equation (5) is a "two-level random intercept model" with trees (level 1) nested within plots (level 2). For the $U_{0 \mathrm{p}}$, just as is the case for the $R_{\mathrm{tp}}$, it is assumed they are drawn from normally distributed populations and the population variance of the lower level residuals $\left(R_{\mathrm{tp}}\right)$ is likewise assumed to be constant across trees. Note that the mean value of $U_{0 \mathrm{p}} \equiv 0$ for the dataset as a whole. As is the normal case in any leastsquares regression model, within each plot the mean $R_{\mathrm{tp}}=0$.

Although Eq. (5) allows for different plots to have different intercepts through the random $U_{0 \mathrm{p}}$ term, it also specifies an invariant slope for the $H: D$ scaling relationship (i.e., independent of plot). A plot-dependent (random) slope effect does, however, turn out to be important as part of the current study (see Sects. 3.1 and 3.2) and can be incorporated by taking $\beta_{\mathrm{lp}}=\gamma_{10}+U_{\mathrm{lp}} \log \left(D_{\mathrm{lp}}\right)$ and then adding the additional random term to Eq. (5) to give

$$
\log \left(H_{\mathrm{tp}}\right)=\gamma_{00}+\gamma_{10} \log \left(D_{\mathrm{tp}}\right)+U_{0 \mathrm{p}}+U_{1 \mathrm{p}} \log \left(D_{\mathrm{tp}}\right)+R_{\mathrm{tp}}
$$

We refer to Eq. (6) as a "pantropical" equation. Associated with the random terms is variability at both the plot and the tree level as well as a covariance between $U_{0 \mathrm{p}}$ and $U_{\mathrm{lp}}$. We denote the associated variances (var) and the level 2 (plot) covariance (cov) as

$\operatorname{var}\left(R_{\mathrm{tp}}\right)=\sigma^{2}, \quad \operatorname{var}\left(U_{0 \mathrm{p}}\right)=\tau_{0}^{2}, \quad \operatorname{var}\left(U_{1 \mathrm{p}}\right)=\tau_{1}^{2}$

$\operatorname{cov}\left(U_{0 \mathrm{p}}, U_{1 \mathrm{p}}\right)=\tau_{01}$.

Equations (6 and 7) form the basis of our analysis, but with Eq. (6) subsequently modified, in the following steps, to examine how continental or regional location, climate and stand structure also modulate the $H: D$ relationship. For example, effects of stand structure and climate can be included by adding new terms to Eq. (6) viz.

$$
\begin{aligned}
\log \left(H_{\mathrm{tp}}\right) & =\gamma_{00}+\varsigma_{01} A+\sum_{E=1}^{M} \eta_{0 \mathrm{E}}+\gamma_{10} \log \left(D_{\mathrm{tp}}\right)+\left[U_{0 \mathrm{p}}\right. \\
& \left.+U_{1 \mathrm{p}} \log \left(D_{\mathrm{tp}}\right)+R_{\mathrm{tp}}\right]
\end{aligned}
$$

where $\varsigma_{01}$ is an additional fixed-effect "intercept" term describing the effect of $A$ and $M$ is the number of environmental variables $(E)$ examined, and with $\eta_{0 \mathrm{E}}$ being the associated additional fixed effect "intercept" terms for the environmental effects. We refer to Eq. (8) as a "pantropical-environmentstructure" equation where the first three terms represent the (fixed) intercept effects, the next term defining the (fixed) slope effect and the three last (square bracketed) terms representing the random (plot and residual) effects.

Alternatively, fixed-effect "continent" terms can be included using categorical (indicator) variables. For example, contrasting continents with indicator variables then set 0 for Asia, 1 for Australia, 2 for Africa, and 3 for South America and affecting both the slope and intercept terms. Expressed formally this is

$$
\begin{aligned}
\log \left(H_{\mathrm{tp}}\right) & =\gamma_{00}+\gamma_{10} \log \left(D_{\mathrm{tp}}\right)+\sum_{C=1}^{N-1}\left[\gamma_{0 \mathrm{C}}+\gamma_{1 \mathrm{C}} \log \left(D_{\mathrm{tp}}\right)\right] \\
& +\left[U_{0 \mathrm{p}}+U_{1 \mathrm{p}} \log \left(D_{\mathrm{tp}}\right)+R_{\mathrm{tp}}\right]
\end{aligned}
$$

where $C$ is an indicator variable as described above and $N$ is the number of continents sampled (in this case four). Within Eq. (9), a tree within a given plot is given a value of 1 if that plot is located within the relevant continent but zero otherwise. We refer to Eq. (9) as a "continent" level equation. It is also possible to include effects such as stand structure and climate within the continental level equations, such that

$$
\begin{aligned}
\log \left(H_{\mathrm{tp}}\right) & =\gamma_{00}+\gamma_{10} \log \left(D_{\mathrm{tp}}\right)+\sum_{C=1}^{N-1}\left[\gamma_{0 \mathrm{C}}+\gamma_{1 \mathrm{C}} \log \left(D_{\mathrm{tp}}\right)\right] \\
& +\zeta_{01} A+\sum_{E=1}^{M} \eta_{0 \mathrm{E}}+\left[U_{0 \mathrm{p}}+U_{1 \mathrm{p}} \log \left(D_{\mathrm{tp}}\right)+R_{\mathrm{tp}}\right]
\end{aligned}
$$

giving a "continent-environment-structure" equation. 
Also considered here are equations based on a simple forest moisture class classification (viz. "Dry", "Moist" and "Wet") rather than environmental variables (Sect. 2.1.4) as has been applied, for example, by Chave et al. (2005). We refer to these as "classification" equations. For example, a "continent-classification-structure" equation is

$$
\begin{aligned}
\log \left(H_{\mathrm{tp}}\right) & =\gamma_{00}+\gamma_{10} \log \left(D_{\mathrm{tp}}\right)+\sum_{C=1}^{N-1}\left[\gamma_{0 \mathrm{C}}+\gamma_{1 \mathrm{C}} \log \left(D_{\mathrm{tp}}\right)\right] \\
& +\varsigma_{01} A+\sum_{\kappa=1}^{J-1} \chi_{0 \mathrm{~F}}+\left[U_{0 \mathrm{p}}+U_{\mathrm{lp}} \log \left(D_{\mathrm{lp}}\right)+R_{\mathrm{tp}}\right]
\end{aligned}
$$

where $F$ denotes the forest moisture class as defined by Holdridge (1967), with indicator variable values used here of 0 for "dry forest" $\left(P_{\mathrm{A}} \leq 1.5 \mathrm{~m}\right), 1$ for "moist forest", $\left(1.5 \mathrm{~m}<P_{\mathrm{A}} \leq 3.5 \mathrm{~m}\right)$ and 2 for "wet forest" $\left(P_{\mathrm{A}}>3.5 \mathrm{~m}\right)$, and $\kappa$ defines the number of forest classes (in this case $\kappa=3$ ).

It is also possible to write region-specific $(R)$ equations similar to the continent-specific equations above. For example, at the regional level, Eq. (9) becomes

$$
\begin{aligned}
\log \left(H_{\mathrm{tp}}\right) & =\gamma_{00}+\gamma_{10} \log \left(D_{\mathrm{tp}}\right)+\sum_{R=1}^{J-1}\left[\gamma_{0 \mathrm{R}}+\gamma_{1 \mathrm{R}} \log \left(D_{\mathrm{tp}}\right)\right] \\
& +\varsigma_{01} A+\sum_{E=1}^{M} \eta_{0 \mathrm{E}}+\left[U_{0 \mathrm{p}}+U_{\mathrm{lp}} \log \left(D_{\mathrm{lp}}\right)+R_{\mathrm{tp}}\right]
\end{aligned}
$$

where $J$ is the number of regions (in our case 9) and again with an indicator variable; where here we set Asia $=0$, Australia $=1$, Central Africa $=2$, East Africa $=3$, West Africa $=4$, Brazilian Shield $=5$, East-Central Amazonia $=$ 6 , Guyana Shield $=7$ and West Amazonia $=8$.

Multilevel models were developed using lme in the "R" software platform. Differences between models were evaluated using analysis of variance and comparison of Akaike's Information Criterion (AIC), a tool for model selection where the model with the lowest AIC indicates the best model, i.e. that which offers the best fit whilst penalising for number of parameters (Akaike, 1974).

The most parsimonious models were selected based on analysis of the residuals and AIC. Models were also compared using a "pseudo" $R^{2}$ comparing the random variance terms as in Eq. (7) to those from an "empty model" (with a fitted intercept term only) as explained in Chapt. 7 of Snidjers and Boskers (1999). Model performance was assessed a posteriori as the deviation in predicted values from measured values, $\left(H_{\mathrm{tp}}-\hat{H}_{\mathrm{tp}}\right) / H_{\mathrm{tp}}$, where $\hat{H}_{\mathrm{tp}}$ is the fitted value. To evaluate deviations in model estimates we compared our final models to the only other pantropical moist and wet forest $H: D$ models known to us, as described earlier (Brown et al., 1989), with deviations computed for their data based on the above technique. Stand-level medians were compared to reduce the influence of either unusually large or small trees on comparisons.

\subsubsection{Centering of explanatory data, units, and variable selection}

For the interpretation of results, it is useful for the fitted variables to have an interpretable meaning when the explanatory values equal zero (Snijders and Bosker, 1999). We thus centered the climate and environment explanatory variables by subtracting the grand mean, so that $x=0$ at its average value. As shown in the Appendix, this approach results in no change in the slopes of the fitted relationships, but gives our model intercept an interpretable meaning, this being the natural logarithm of $H$ when $D=1$. It is for this reason we express $D$ here in decimetres rather than than the more usually referred to centimetres; our model intercepts then being interpretable as $\log (H)$ at the often used minimum $D$ for forest inventory measurements (Phillips et al., 2010).

For the models including environmental effects we first tested for significant correlations amongst climatic variables extracted from the $2.5 \mathrm{~min}$ resolution WorldClim dataset, as described in Sect. 2.1 (Hijmans et al., 2005) and selected a preliminary subset of non-correlated variables. Tree density $\left(\mathrm{ha}^{-1}\right.$ ) and $A$ for stems $\geq 1 \mathrm{dm}$ were both tested as forest structural variables. Statistical models were then tested in a forward selection fashion with a step-wise removal of explanatory variables that did not improve the model. Tree density was always non-significant and significant environmental variables included $P_{\mathrm{V}}, S_{\mathrm{D}}$, and $T_{\mathrm{A}}$. Interestingly, $P_{\mathrm{V}}$ proved to be a stronger predictor than mean annual precipitation for all models tested.

\subsubsection{Goodness of fit and residual analysis}

In order to evaluate any biases in the models, level 2 (plot) residuals were examined as a function of $A, P_{\mathrm{V}}, S_{\mathrm{D}}$, and $D$, as well as versus $P_{\mathrm{A}}$ and $A_{\mathrm{L}}$ as shown for the regionenvironment-structure model the Supplement, (Fig. S3). Further to this, we also investigated possible relationships between plot level residuals and a range of soil fertility and physical characteristics for the 81 plots for which such data were available (Sect. 2.3). These analyses were performed for both the pantropical-environment-structure and regionalenvironment-structure models using robust nonparametric regression techniques (Terpstra and McKean, 2005; McKean et al., 2009).

\section{Results}

\subsection{Tree height, continent and climate}

\subsubsection{Global and continental patterns}

Tree height variations are summarised in Fig. 2, with trees partitioned according to three diameter classes $(D<2 \mathrm{dm}$, $2<D<4 \mathrm{dm}$ and $D>4 \mathrm{dm}$ ) and separated according to forest moisture classification as described in Sect. 2.4. Notable differences between the different continents are evident. For 

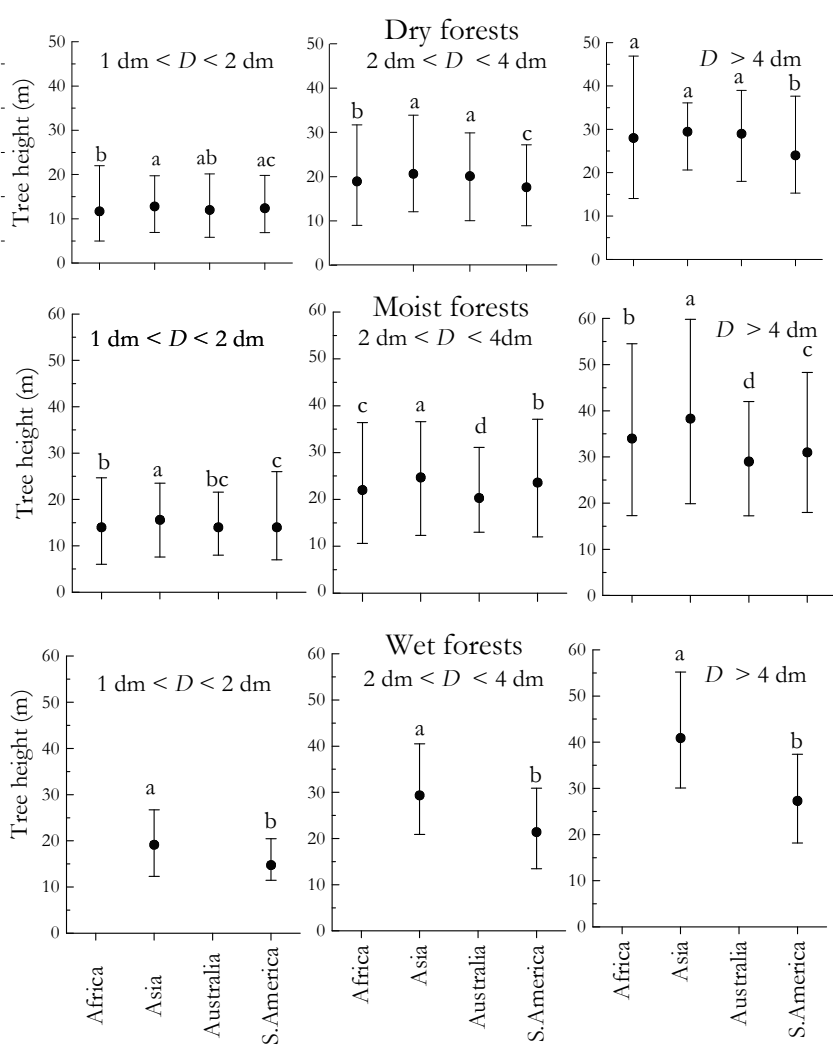

Fig. 2. Tree height distribution by diameter class and continent for dry, moist, and wet forests in Africa, Asia, Australia and South America. Bars indicate upper and lower 0.05 quantiles. Different letters within each panel indicate significant differences $(p<0.05)$.

example, for the smallest $D$ class the median height for moist forest trees in South America is $1.6 \mathrm{~m}$ less than for Asia $(p<0.05)$ with trees from Asia generally taller than other continents: Differences for moist and wet forest trees are substantial at $D>4 \mathrm{dm}$ with moist forest Asian trees having a median height $4.3 \mathrm{~m}$ taller than in those in Africa, $7.3 \mathrm{~m}$ taller than those in South America and $9.3 \mathrm{~m}$ taller than Australia. Even more impressive are the differences between wet forests for this highest diameter class for which Asian tropical forest trees have a median height of $40.9 \mathrm{~m}$; this being about $50 \%$ greater than the median of $27.3 \mathrm{~m}$ observed for South American forests.

\subsubsection{Pantropical model}

Results from fitting the pantropical model of Eq. (5) are shown in the first data column of Table 2, for which we obtain $\gamma_{00}=2.45$. It then readily follows that $\hat{H}$ for $D=1 \mathrm{dm}$ is $e^{2.45}=11.6 \mathrm{~m}$; this being the predicted tree height at $D=1$ $\mathrm{dm}$ taken across the entire dataset. The fitted scaling coefficient of 0.53 is much less than unity. Thus, for a doubling of $D$ to $2 \mathrm{dm}, \hat{H}$ increases only to $16.7 \mathrm{~m}$ whilst for $D=4 \mathrm{dm}$ $\hat{H}$ becomes $24.2 \mathrm{~m}$.
The intercept variance associated with plot location, $\tau_{0}^{2}$, is estimated at 0.178 and over three times the residual term associated with the tree-to-tree (within-plot) variability $\left(\sigma^{2}=\right.$ $0.054)$. That is to say, different plots differ considerably in their intercept terms. Estimating the lower and upper 0.1 quantiles as $\hat{H} \pm 1.3 \tau_{0}$ (Snijders and Bosker, 1999) gives $10 \%$ of all plots having an average tree height $(D=1 \mathrm{dm})$ of $6.7 \mathrm{~m}$ or lower. For a plot with a typically high intercept $(0.9$ quantile) the equivalent estimate is $19.9 \mathrm{~m}$. A similar calculation can be undertaken for the random slope term, $\tau_{12}$, where the equivalent confidence interval ranges from 0.47 to 0.67 . Thus, the plot within which a tree is located exerts a strong influence on its $H: D$ allometry - this to a large degree also being shared by other trees in the same plot.

\subsubsection{Pantropical-structure-environment model}

The second column of Table 2 shows the effect of the addition of stand structure and climate to the pantropical model. The fitted model can be written in terms of its fixed effects only:

$$
\begin{aligned}
\log (H) & =2.53+0.0098 \tilde{A}+0.337 \tilde{P}_{\mathrm{V}}-0.063 \tilde{S}_{\mathrm{D}} \\
& +0.020 \tilde{T}_{\mathrm{A}}+0.53 \log (D)
\end{aligned}
$$

which provides a simple general equation describing the relationship between $H(\mathrm{~m})$ and $D(\mathrm{dm})$ for individual trees accounting for effects of stand basal area $(A)$, precipitation coefficient of variation $\left(P_{\mathrm{V}}\right)$, dry season length $\left(S_{\mathrm{D}}\right)$, and mean annual temperature $\left(T_{\mathrm{A}}\right)$. Note the tilde above each of the four intercept-modifying terms in Eq. (13). This is to signify that, for this equation (and all equations in the main text), the stand structural and environmental variables have been centered to aid interpretation of the fitted parameters. Corresponding "non-centered" equations applicable for practical use in the field along with their method of derivation are given in the Appendix.

The addition of stand-level basal area $(A)$ to the model as an intercept term is important, with the estimate of $0.0098 \pm$ 0.001 being highly significantly different from zero. The intercept term of the regression also increases with $P_{\mathrm{V}}$ but declines with $S_{\mathrm{D}}$. Temperature also affects the intercept term; with all else being equal, trees in stands growing at a higher $T_{\mathrm{A}}$ tending to have a greater $H$ at any given $D$.

The inclusion of the three climate variables and $A$ results in a large improvement in the model fit relative to the pantropical model (based on diameter alone), as can be seen through comparison of the models' AIC, with much of the plot-to-plot variability in the intercept and slope of the pantropical model accounted for by stand structure and climate, as evidenced by the large reduction observed in the plot-level residual terms, especially $\tau_{0}^{2}$. No significant effect of any environmental or structural parameter was found for the slope of the $\log (H): \log (D)$ relationship. Thus, environment and stand structure do not affect the allometric scaling 
Table 2. Effect of continent, forest structure and climate on model estimates of the relationship between tree height $(\ln (H)$, $\mathrm{m})$ and diameter $(\ln (D), \mathrm{dm})$ for grand-mean-centered structural and environmental data, including the effect of hierarchical structure (random: plot). For the continent based models the base value is Asia with the continent-classification-structure model also having dry forests as an additional base value. Significant terms are bold $(p<0.05)$. Precipitation dry season $\left(S_{\mathrm{D}}\right.$, months $)$, precipitation coefficient of variance $\left(P_{\mathrm{V}}\right)$, mean annual temperature $\left(T_{\mathrm{A}},{ }^{\circ} \mathrm{C}\right)$, forest moisture class $\left(F_{\mathrm{M}}\right.$, dry, moist, wet $)$, tree basal area $\left(A, \mathrm{~m}^{2} \mathrm{ha}^{-1}\right)$. NA: not applicable. See Appendix A for working equations.

\begin{tabular}{|c|c|c|c|c|c|c|c|c|c|c|}
\hline \multirow[b]{2}{*}{ Fixed effects } & \multicolumn{2}{|c|}{$\begin{array}{l}\text { Pantropical- } \\
\text { Only }\end{array}$} & \multicolumn{2}{|c|}{$\begin{array}{c}\text { Pantropical- } \\
\text { environment-structure }\end{array}$} & \multicolumn{2}{|c|}{$\begin{array}{l}\text { Continental- } \\
\text { Only }\end{array}$} & \multicolumn{2}{|c|}{$\begin{array}{l}\text { Continent- } \\
\text { environment-structure }\end{array}$} & \multicolumn{2}{|c|}{$\begin{array}{l}\text { Continent- } \\
\text { classification-structure }\end{array}$} \\
\hline & Coeff. & S.E. & Coeff. & S.E. & Coeff. & S.E. & Coeff. & S.E. & Coeff. & S.E. \\
\hline$\gamma_{00}=$ Intercept (pantropical) & 2.4478 & 0.0151 & 2.5302 & 0.013 & & & & & & \\
\hline$\gamma_{00}=$ Intercept (Asia) & & & & & 2.5473 & 0.0483 & 2.5018 & 0.0385 & 2.0212 & 0.0583 \\
\hline$\gamma_{10}=$ Coefficient of $\ln (D):$ (pantropical) & 0.5320 & 0.0070 & 0.5296 & 0.007 & & & & & & \\
\hline$\gamma_{10}=$ Coefficient of $\ln (D):$ (Asia) & & & & & 0.5767 & 0.0200 & 0.5720 & 0.0197 & 0.5714 & 0.0198 \\
\hline$\gamma_{01}=$ Intercept $($ Africa - Asia $)$ & & & & & -0.2224 & 0.0557 & -0.0747 & 0.0463 & -0.1724 & 0.0475 \\
\hline$\gamma_{02}=$ Intercept (Australia-Asia) & & & & & -0.1382 & 0.0674 & -0.1023 & 0.0616 & -0.2935 & 0.0591 \\
\hline$\gamma_{03}=$ Intercept $(\mathrm{S}$. America-Asia $)$ & & & & & -0.0536 & 0.0519 & 0.1112 & 0.0422 & 0.0215 & 0.0449 \\
\hline$\gamma_{11}=$ Coefficient of $\ln (D):($ Africa-Asia $)$ & & & & & 0.0403 & 0.0228 & 0.0436 & 0.0226 & 0.0447 & 0.0227 \\
\hline$\gamma_{12}=$ Coefficient of $\ln (D):($ Australia-Asia $)$ & & & & & -0.0565 & 0.0265 & -0.0559 & 0.0262 & $-\mathbf{0 . 0 5 5 7}$ & 0.0263 \\
\hline$\gamma_{13}=$ Coefficient of $\ln (D):($ S. America - Asia $)$ & & & & & -0.0913 & 0.0216 & -0.0897 & 0.0213 & -0.0877 & 0.0214 \\
\hline$\varsigma_{01}=$ Intercept $(A-32.4): \mathrm{m}^{2} \mathrm{ha}^{-1}$ & & & 0.0098 & 0.0010 & & & 0.0121 & 0.0011 & 0.0120 & 0.0010 \\
\hline$\eta_{01}=$ Intercept $\left(P_{\mathrm{V}}-0.57\right)$ & & & 0.3368 & 0.0009 & & & 0.4647 & 0.0979 & NA & NA \\
\hline$\eta_{02}=$ Intercept $\left(S_{\mathrm{D}}-3.7\right):$ months & & & -0.0632 & 0.0089 & & & -0.0677 & 0.0090 & NA & NA \\
\hline$\eta_{03}=$ Intercept $\left(T_{\mathrm{A}}-24.7\right):{ }^{\circ} \mathrm{C}$ & & & 0.0204 & 0.0055 & & & 0.0157 & 0.0059 & NA & NA \\
\hline$\chi_{01}=$ Intercept (moist forest-dry forest) & & & & & & & & & 0.1804 & 0.0269 \\
\hline$\chi_{02}=$ Intercept $($ wet forest - dry forest $)$ & & & & & & & & & 0.1456 & 0.0652 \\
\hline Random effects & Var. comp. & S.E. & Var. comp. & S.E. & Var. comp. & S.E. & Var. comp. & S.E. & Var. comp. & S.E. \\
\hline \multicolumn{11}{|l|}{ Level-two (plot) random effects: } \\
\hline$\tau_{0}^{2}=\operatorname{var}\left(U_{0 \mathrm{p}}\right)$ & 0.1782 & 0.0251 & 0.0377 & 0.0115 & 0.0541 & 0.0138 & 0.0318 & 0.0106 & 0.0369 & 0.0114 \\
\hline$\tau_{1}^{2}=\operatorname{var}\left(U_{1 \mathrm{p}}\right)$ & 0.0102 & 0.0060 & 0.0100 & 0.0060 & 0.0065 & 0.0048 & 0.0063 & 0.0047 & 0.0064 & 0.0047 \\
\hline$\tau_{01}=\operatorname{cov}\left(U_{0 \mathrm{p}}, U_{1 \mathrm{p}}\right)$ & -0.0374 & & -0.0126 & & -0.0095 & & -0.0082 & & -0.0084 & \\
\hline \multicolumn{11}{|l|}{ Level-one (residual) variance: } \\
\hline$\sigma^{2}=\operatorname{var}\left(R_{t} p\right)$ & 0.0536 & 0.0138 & 0.0536 & & 0.0536 & 0.0138 & 0.0536 & 0.0138 & 0.0536 & 0.0138 \\
\hline AIC & -1861.2 & & -2037.4 & & -1945.6 & & -2122.6 & & -2068.9 & \\
\hline
\end{tabular}

coefficient itself. But rather, simply the intercept term, readily interpretable here as $\log (H)$ at $D=1 \mathrm{dm}$.

\subsubsection{Continental-level models}

The third column of Table 2 shows the results from a second approach, where continent has been included as an indicator variable as in Eq. (9) with the fixed effect "continent" terms significantly modulating both the slope and intercept of the $\log (H): \log (D)$ relationship. With the same random effects structure retained as for the pantropical model of Eq. (7), a significant improvement relative to the pantropical model (based on diameter alone) was observed as shown by the significant decrease in AIC from -1861 to -1945 and the reductions in all level-two (plot) residual effects. Nevertheless, the inclusion of the geographically explicit "continent" terms did not provide as much explanatory power as the addition of climate and stand structure variables to the pantropical model $(\mathrm{AIC}=-2037)$.

This continental model highlights significant differences between some of the fixed-effect parameters amongst continents. Specifically, models for South America and Asia have statistically similar intercepts, but the intercept term is significantly lower for both Australia and Africa. On the other hand, H:D models for Asia and Africa have similar slopes, both of which are significantly higher than for Australia and South America.

Given the clear effects of both continental location and environment/structure on $H: D$ allometry we joined the two to see the overall effect, this being the continent-environmentstructure model of Column 4 of Table 2. Here some of the parameter values are significantly different compared to the preceding models, with a further reduction in the variance associated with the level-2 plot variance intercept term. Overall, the importance of accounting for continental location, climate and structure as intercept terms can be seen by this substantially lower plot-level intercept variance of 0.032 , as compared to 0.178 for the simple pantropical model.

The final column of Table 2 shows the results for the continent-classification-structure of Eq. (10). Here we have eliminated the climate variables in the continentalenvironment-structure forest-structure model by simply assigning forests to three moisture classes (dry, moist, wet). This simple classification produced highly significant estimates for the associated $\chi_{01}$ and $\chi_{02}$ intercept terms and estimates for the values of the other fixed terms that were nearly identical to the values for the continental-climatestructure model, although with a slightly inferior AIC. 
Table 3. Effect of region, forest structure and climate on model estimates of the relationship between the natural logarithm of tree height, $\log (H)$ - measuremed in metres, and the natural logarithm of diameter at breast height, $\log (D)$ - measured in decimetres, for grand-meancentered structural and environmental data. For the region-based models the base value is Asia with the region-classification-structure model also having dry forests as an additional base value. Significant terms are bold $(p<0.05)$. Precipitation dry season $\left(S_{\mathrm{D}}\right.$ : months $)$, precipitation coefficient of variance $\left(P_{\mathrm{V}}\right)$, mean annual temperature $\left(T_{\mathrm{A}}:{ }^{\circ} \mathrm{C}\right)$, forest moisture class $\left(F_{\mathrm{M}}\right.$ : dry, moist, wet), tree basal area $\left(A, \mathrm{~m}^{2}\right.$ ha $\left.{ }^{-1}\right)$ NA: not applicable. See Appendix A for working equations.

\begin{tabular}{|c|c|c|c|c|c|c|}
\hline \multirow[b]{2}{*}{ Fixed effects } & \multicolumn{2}{|c|}{$\begin{array}{l}\text { Region } \\
\text { Only }\end{array}$} & \multicolumn{2}{|c|}{$\begin{array}{c}\text { Region- } \\
\text { environment-structure }\end{array}$} & \multicolumn{2}{|c|}{$\begin{array}{c}\text { Region- } \\
\text { forest-structure }\end{array}$} \\
\hline & Coeff. & S.E. & Coeff. & S.E. & Coeff. & S.E. \\
\hline$\gamma_{00}=$ Intercept $($ Asia $)$ & 2.5470 & 0.0424 & 2.5182 & 0.0368 & 2.0757 & 0.0530 \\
\hline$\gamma_{10}=$ Coefficient of $\ln (D)$ : (Asia) & 0.5782 & 0.0191 & 0.5736 & 0.0190 & 0.5729 & 0.0190 \\
\hline$\gamma_{01}=$ Intercept $($ Central Africa-Asia $)$ & -0.1172 & 0.0603 & 0.0322 & 0.0561 & -0.0858 & 0.0530 \\
\hline$\gamma_{02}=$ Intercept $($ E. Africa-Asia $)$ & -0.3698 & 0.0612 & -0.1987 & 0.0683 & -0.2984 & 0.0559 \\
\hline$\gamma_{03}=$ Intercept $($ W. Africa - Asia $)$ & -0.1868 & 0.0584 & -0.1313 & 0.0494 & -0.1488 & 0.0505 \\
\hline$\gamma_{04}=$ Intercept $($ Brazilian Shield Amazonia-Asia $)$ & -0.0943 & 0.0558 & 0.1062 & 0.0528 & 0.0334 & 0.0494 \\
\hline$\gamma_{05}=$ Intercept $($ East-Central Amazonia-Asia) & -0.2229 & 0.0525 & -0.0116 & 0.0488 & -0.1185 & 0.0477 \\
\hline$\gamma_{06}=$ Intercept $($ Guyana Shield - Asia $)$ & 0.1482 & 0.0562 & 0.1938 & 0.0475 & 0.1824 & 0.0490 \\
\hline$\gamma_{07}=$ Intercept $($ West Amazonia-Asia $)$ & 0.0080 & 0.0528 & 0.0971 & 0.0452 & 0.0283 & 0.0461 \\
\hline$\gamma_{09}=$ Intercept (Australia- Asia) & -0.1385 & 0.0590 & -0.1456 & 0.0664 & -0.2786 & 0.0529 \\
\hline$\gamma_{11}=$ Coefficient of $\ln (D)$ : (Central Africa-Asia $)$ & -0.0235 & 0.0277 & -0.0218 & 0.0275 & -0.0202 & 0.0275 \\
\hline$\gamma_{12}=$ Coefficient of $\ln (D):$ (E. Africa-Asia) & 0.0739 & 0.0270 & 0.0779 & 0.0268 & 0.0785 & 0.0268 \\
\hline$\gamma_{13}=$ Coefficient of $\ln (D):($ W. Africa-Asia $)$ & 0.0583 & 0.0254 & 0.0626 & 0.0252 & 0.0633 & 0.0252 \\
\hline$\gamma_{14}=$ Coefficient of $\ln (D):($ Brazilian Shield-Asia $)$ & -0.1131 & 0.0251 & -0.1089 & 0.0249 & -0.1102 & 0.0249 \\
\hline$\gamma_{15}=$ Coefficient of $\ln (D)$ : (E-Central Amazonia-Asia) & -0.0710 & 0.0252 & -0.0800 & 0.0250 & -0.0747 & 0.0250 \\
\hline$\gamma_{16}=$ Coefficient of $\ln (D):($ Guyana Shield-Asia $)$ & -0.0797 & 0.0248 & -0.0735 & 0.0246 & -0.0727 & 0.0246 \\
\hline$\gamma_{17}=$ Coefficient of $\ln (D)$ : (West Amazonia-Asia) & -0.1113 & 0.0241 & -0.1070 & 0.0240 & -0.1065 & 0.0240 \\
\hline$\gamma_{19}=$ Coefficient of $\ln (D):$ (Australia-Asia) & -0.0568 & 0.0253 & -0.0565 & 0.0252 & -0.0561 & 0.0251 \\
\hline$\varsigma_{01}=$ Intercept $(A-32.4): \mathrm{m}^{2} \mathrm{ha}^{-1}$ & & & 0.0120 & 0.0011 & 0.0109 & 0.0010 \\
\hline$\eta_{01}=$ Intercept $\left(P_{\mathrm{V}}-0.57\right)$ & & & 0.3360 & 0.1017 & NA & NA \\
\hline$\eta_{02}=$ Intercept $\left(S_{\mathrm{D}}-3.7\right):$ months & & & -0.0449 & 0.0094 & NA & NA \\
\hline$\eta_{03}=\operatorname{Intercept}\left(T_{\mathrm{A}}-24.7\right):{ }^{\circ} \mathrm{C}$ & & & 0.0191 & 0.0076 & NA & NA \\
\hline$\chi_{01}=$ Intercept $($ moist forest - dry forest $)$ & & & & & 0.1533 & 0.0286 \\
\hline$\chi_{02}=$ Intercept $($ wet forest-dry forest $)$ & & & & & 0.1368 & 0.0603 \\
\hline Random effect & Var. comp. & S.E. & Var. comp. & S.E. & Var. comp. & S.E. \\
\hline \multicolumn{7}{|l|}{ Level-two (plot) random effects: } \\
\hline$\tau_{0}^{2}=\operatorname{var}\left(\mathrm{U}_{0 \mathrm{p}}\right)$ & 0.0407 & 0.0120 & 0.0275 & 0.0099 & 0.0289 & 0.0101 \\
\hline$\tau_{1}^{2}=\operatorname{var}\left(\mathrm{U}_{1 \mathrm{p}}\right)$ & 0.0058 & 0.0045 & 0.0057 & 0.0045 & 0.0057 & 0.0045 \\
\hline$\tau_{01}=\operatorname{cov}\left(\mathrm{U}_{0 \mathrm{p}}, \mathrm{U}_{1 \mathrm{p}}\right)$ & -0.0081 & & -0.0072 & & -0.0075 & \\
\hline \multicolumn{7}{|l|}{ Level-one (residual) variance } \\
\hline$\sigma_{2}=\operatorname{var}\left(\mathrm{R}_{\mathrm{tp}}\right)$ & 0.0536 & 0.0138 & 0.0536 & 0.0138 & 0.0536 & 0.0138 \\
\hline AIC & -2027.9 & & -2156.0 & & -2147.1 & \\
\hline
\end{tabular}

\subsection{Regional-level models}

Figure 3 summarizes the tree height data by region, with trees again partitioned according to three size classes $(D<2 \mathrm{dm}$, $2 \leq D \leq 4 \mathrm{dm}$ and $D>4 \mathrm{dm}$ ) and according to the forest moisture classification as described above. This shows that in dry forests the median height of trees in the smallest $D$ class ( 1 to $2 \mathrm{dm} D$ ) on the Guyana Shield is significantly greater than trees in East and West Africa, on the Brazilian Shield and in Australia. For moist forests, the tallest trees in this size-class were encountered on the Guyana Shield and in Western Amazonia and the shortest in Eastern Africa and Eastern-Central Amazonia. Wet forest trees in Asia from this same $D$ class had a median height $4 \mathrm{~m}$ taller than those in Western Amazonia. For trees with $D>4 \mathrm{dm}$, differences are even more substantial $(14 \mathrm{~m})$. The tallest dry forest trees were found in Western Africa (median $33.8 \mathrm{~m}$ ) and Asia $(29.5 \mathrm{~m})$, with the former having a median height $9.8 \mathrm{~m}$ greater than dry-forest trees on the Brazilian Shield. In moist forests, the tallest trees were measured in Asia, Central and Western Africa, and on the Guyana Shield. 

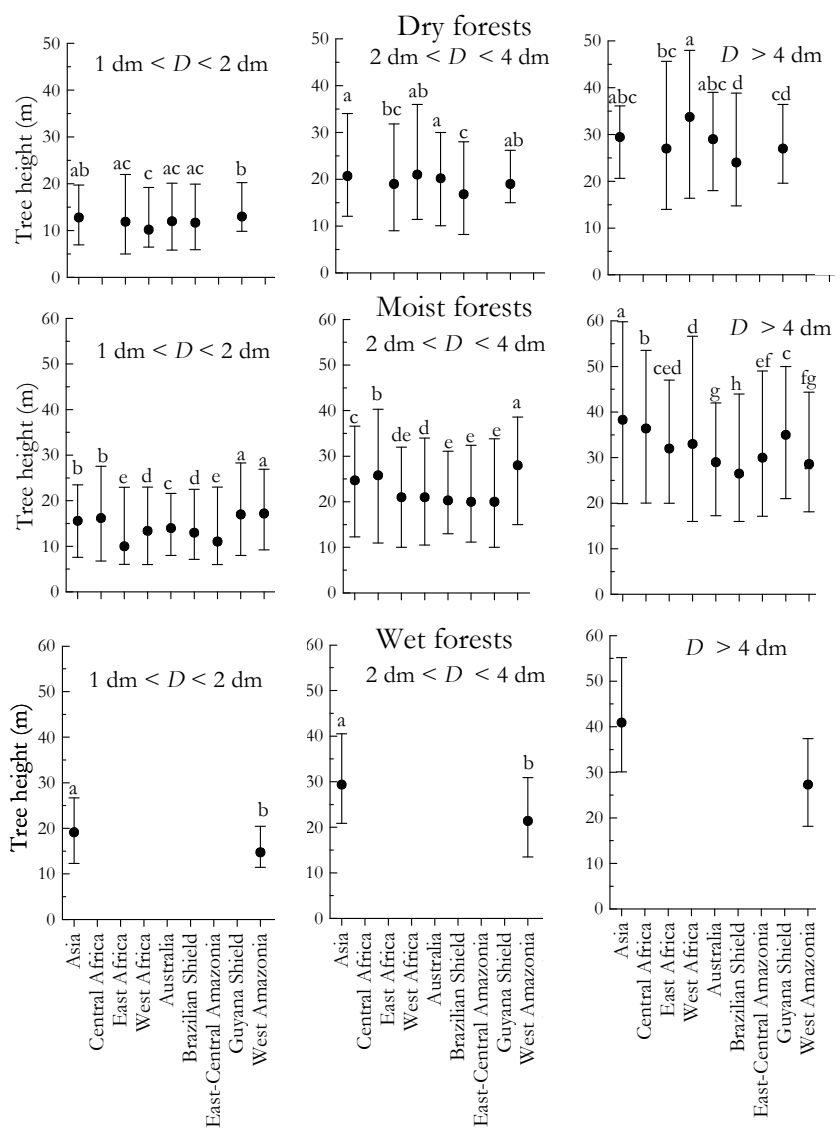

Fig. 3. Tree height distribution by diameter class and region for dry, moist, and wet forests. Bars indicate upper and lower 0.05 quantiles. Different letters within each panel indicate significant differences $(p<0.05)$.

Similar to the models that included continent, assigning region as a fixed effect while retaining plot as a random effect also resulted in significant improvement in the model relative to the multilevel model based on $D$ alone, with significant differences among regions and with $A$, and climate variables also being significant (Table 3). Nevertheless, comparing the AIC and the plot random-effect terms of the continentallevel models (Table 2), the overall improvement with this increased level of complexity, although significant, was also relatively modest (AIC of -2156 versus -2127 ), with the coefficients for the structural and environmental parameters hardly changed.

Figure 4 illustrates the ability of the region-environmentstructure model to predict stand-level height from diameter measurements. Here we have estimated $H$ from associated $D$ on the same tree and then presented each plot's median $\hat{H}$ so predicted (denoted $\stackrel{\Delta}{H}$ ) against the actual measured median height, $\stackrel{\cap}{H}$. This shows that the region-environment-structure model successfully predicts $\stackrel{\cap}{H}$, except for some of the tallest

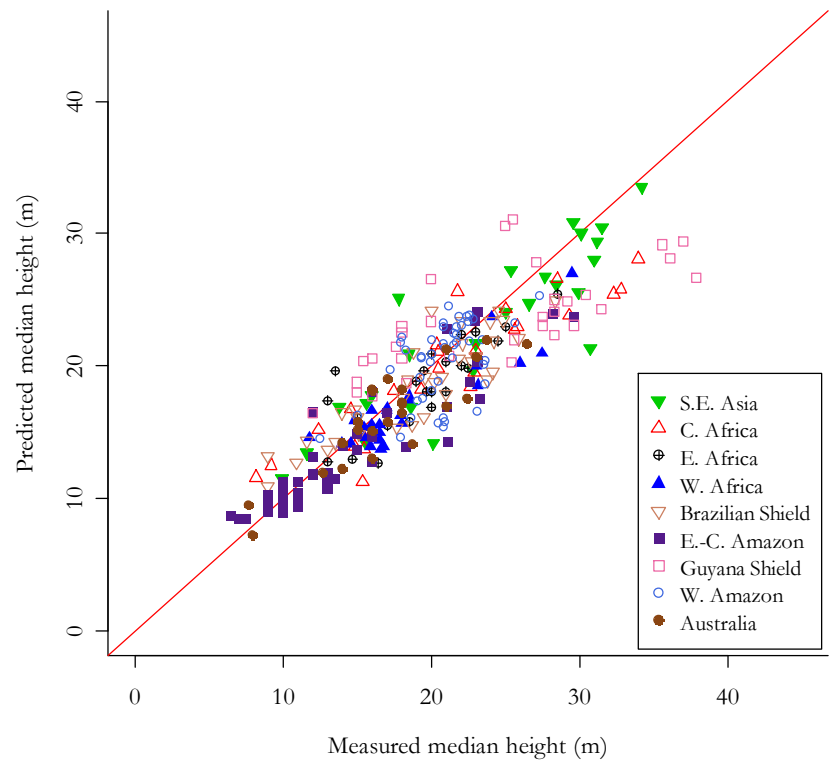

Fig. 4. Median predicted tree height versus measured tree height by plot for the region-environment-structure model. The solid red line indicates the 1:1 relationship.

stands on the Guyana Shield where $\stackrel{\Delta}{H}$ is an underestimate of $\stackrel{\cap}{H}$. Plots of the model residuals versus $A, P_{\mathrm{V}}, S_{\mathrm{D}}$ and $D$, as well as versus annual precipitation, are presented in the Supplement, (Fig. S3). This shows the model to provide a reliable, unbiased estimate of tree heights across a wide range of environmental conditions and stand basal areas. The explained variance of the region-environment-structure model as quantified by the calculation of a "pseudo" $R^{2}$ gives an $R^{2}$ for level 1 (within plots) of 0.61 and a level-2 (between-plot) $R^{2}$ of 0.80 .

The modelled relationship between the region-only and region-environment-structure model (the latter with all centered structural/environmental terms set to zero) are shown in Fig. 5a and b, respectively. Figure 5a can be considered to show the differences observed in the average $H: D$ relationship for the different regions with Fig. 5b showing the results of subtracting the effects of environment and forest structure from these observed regionally dependent relationships. Figure $5 \mathrm{~b}$ suggests a broad separation of the nine regions into two fundamental groups. Those with a higher $\hat{H}$ at any given $D$ are the three African regions, Asia and the Guyana Shield, and the remaining South American regions (East-Central and Western Amazonia, Brazilian Shield) and Australia forming a second group with low $H$. It would seem reasonable to conclude then, that most of the difference between the regionaland continental-level models is due to trees in the forests on the Guyana Shield having $\hat{H}: D$ allometry that is more similar to that of trees in the forests of Asia and Africa than their geographically closer South and Central American counterparts. This is also evident from close examination of Fig. 3. 

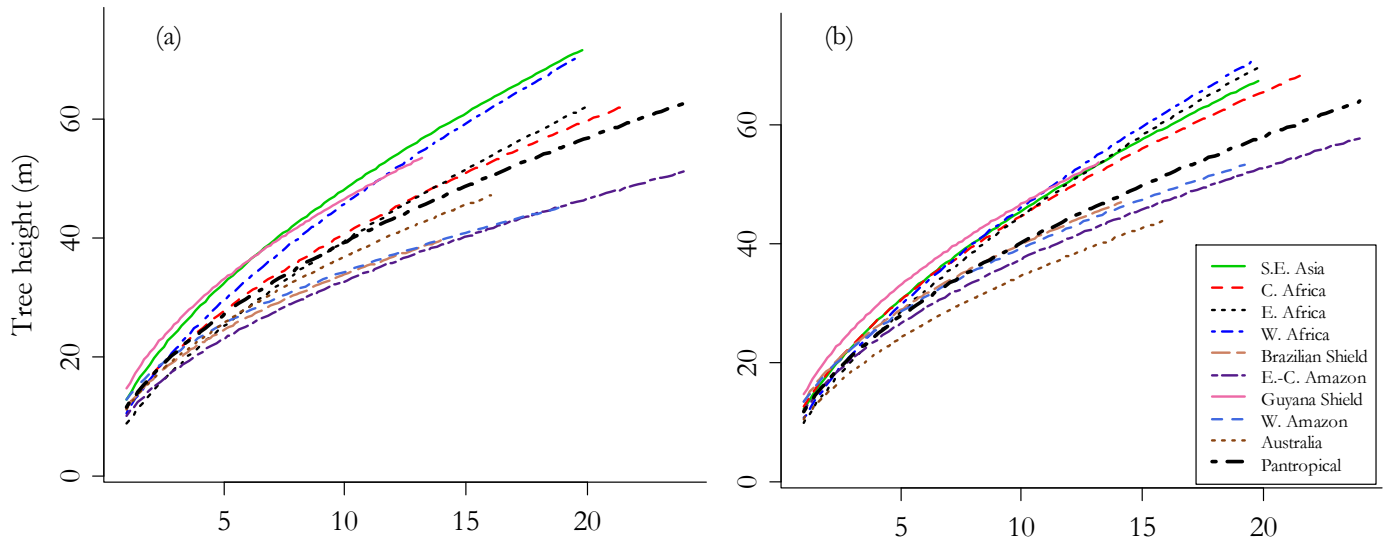

Diameter $(\mathrm{dm})$

Fig. 5. Model predictions showing fitted relationship between tree height $(H)$ and diameter $D$ for the different regions (a) region-only model; (b) region-environment-structure model. Also shown in each panel is the associated pantropical model (pantropical only or pantropicalenvironment-structure), this showing the relationship between $H$ and $D$ for the dataset as a whole.

\subsection{Plot-to-plot variation}

Although the estimated 0.8 of the between-plot variance accounted for by the regional-environment-structure model is quite high, it was also of interest to evaluate whether the remaining 0.2 could be related to other factors; some aspect of soil physical and/or chemical properties being the most obvious candidates. Detailed soil data are available for a large number of South American sites sampled as part of the RAINFOR network (Quesada et al., 2010), with additional soil data and soil profile descriptions from some of the sites included in the $H: D$ analyses above having been collected in Australia, Bolivia, Brazil, Brunei, Cameroon, French Guiana, Ghana, Malaysia and Peru over recent years and analyzed with the same methodology.

Although an examination of the relationships between soil chemistry (exchangeable cations, total soil $\mathrm{P}$, soil $\mathrm{C} / \mathrm{N}$ ), soil texture and variability in plot-effect terms revealed no statistically significant relations $(p>0.05)$, robust regression techniques revealed plot intercept terms to be related to the index of soil physical properties developed by Quesada et al. (2010), a measure of effective soil depth, soil structure, topography and anoxia. Fig. 6 shows that the random plot intercept term for both the continent-environment-structure and regional-environment-structure models declines significantly as $\Pi$ increases, with the relationship being stronger for the former $(P<0.001$ versus $P<0.05)$. Interestingly, many of the lower outliers in the regional-environment-structure model plot (Fig. 6b) were identified as forests existing at the lowest rainfall extremes for their region, generally existing with savanna/forest transition zones.

The random slope intercept, although showing a slight tendency to increase with $\Pi$, showed no overall statistically significant relationship with $\Pi$ for the regional-environment- structure model and only being significant at $P<0.05$ for the continent-environment-structure model.

\section{Discussion}

\subsection{Comparison with other models}

Based on our preliminary analyses as provided in the Supplement, we chose a $\log (H): \log (D)$ model for our analysis only after also considering other commonly applied tropical $H: D$ allometric functions. Such equations included a combination of log-linear and asymptotic forms of up to three parameters (Bullock, 2000; Thomas, 1996; Bailey, 1980; Fang and Bailey, 1998). Although it has been suggested that lognormal and log-log relationships often do equally well in fitting height to diameter, we found that log-normal relationships were insufficient for normalizing data and had higher deviation than $\log -\log$ models.

Cessation of tree height growth in older trees (Kira, 1978) and relatively similar individual tree canopy heights within sites has given rise to calls for the application of asymptotic curve-fitting to model monotonic $H: D$ relationships (Bullock, 2000). For individual species, girth continues to increase while height remains virtually constant. This height model selection based on biologically meaningful parameters such as species maximum height $\left(H_{\max }\right)$ has the advantage of allowing for $H_{\max }$ comparisons between species and for the evaluation of inter-relationships between structural attributes and functional groups. For example, $H_{\max }$ may correlate with the architectural, physiological and demographic traits of coexisting species (Thomas, 1996; Thomas and Bazzaz, 1999; Poorter et al., 2003, 2006; Kohyama et al., 2003). Nevertheless, it is generally only large-statured species that tend to show asymptotic $H: D$ relationships (Iida et al., 2011) 


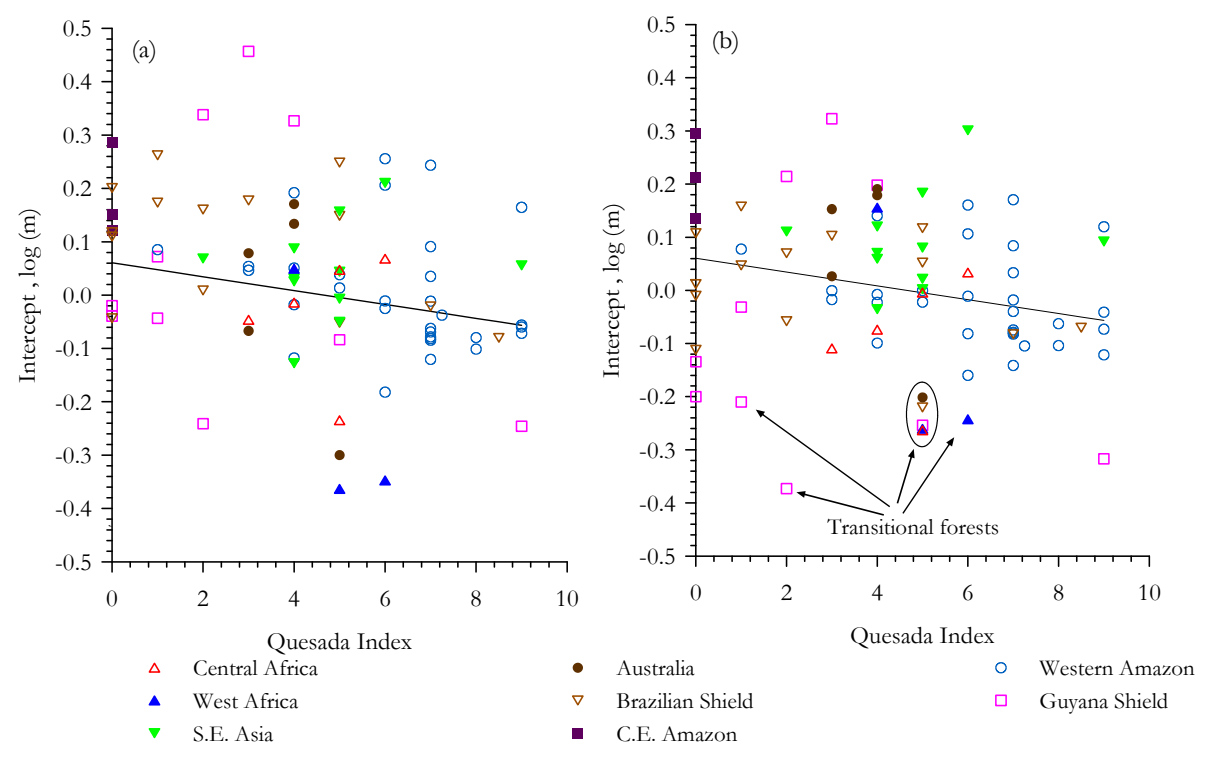

Fig. 6. Relationship between plot-level intercept residual terms and the Quesada et al. (2010) index of soil physical properties (a) pantropicalenvironment-structure model; (b) regional-environment-structure model.

and Poorter et al. (2006) found that approximately one-fourth of the species examined in a Bolivian forest failed to exhibit asymptotic $H: D$ relationships. In those species exhibiting asymptotic relations it is unclear whether the reduction in tree height growth with height in mature stands represents the approach to critical maximum height, or alternatively, the response of tall trees attaining a canopy position and reduced competition for light (King, 1990). In any case, because of the wide variation observed in individual species $H: D$ relationships (Poorter et al., 2006), and because of inter-species variations in $H_{\max }$ (Baker et al., 2009), it is unlikely that any single meaningful asymptotic relationship will apply for a typically diverse tropical forest stand. It is probably for this reason that, at the plot level, we found that the asymptotic function failed to consistently converge for dry and wet forests, and that this function grossly overestimated height in many of our forests when the function did converge.

When our pantropical closed-canopy dry and moist forest models are compared to the second most comprehensive pantropical data set (Brown et al., 1989), that being based on 3824 tree measurements, a strikingly close correspondence was indicated between the slope coefficients of the two equations. Although such small differences could be taken to indicate a robust $H: D$ relationship at the pantropical level, thus supporting the theory of a universal $H: D$ scaling relationship (e.g., Niklas and Spatz, 2004), differences in tree architecture become apparent when the Brown moist model is compared to our region-specific models. The Brown moist models only estimate $H$ to within $-22 \%$ to $+4 \%$ of the median of measured values. This is a substantial bias compared to our more sophisticated models that include environment and forest structure to accurately estimate $H$ (Supplement, Table S3, Fig. S2). Moreover, as shown in Table 3, Fig. 5 and discussed further below, significant differences in the $H: D$ scaling exponent also exist for the different tropical regions, even once these variations in stand structure and environment are taken into account.

\subsection{Plot-to-plot variations}

It has been demonstrated that trees exhibit variations in architectural properties, both within and across sites (Nogueira et al., 2008b; Sterck and Bongers, 2001; O'Brien et al., 1995; Osunkoya et al., 2007; Poorter et al., 2003, 2006). The pantropical tree architecture dataset presented here represents a first step towards unifying our understanding of global tree architecture data. Our aim here was to examine whether and how forest structure, geography and climate interact to affect tropical tree $H: D$ allometric relationships. We have found significant differences in $H: D$ allometries at continental and regional scales as well as detecting significant effects of climate and forest structure.

As trees grow taller and crowns extend laterally, trees necessarily invest in stem diameter growth to support large crowns, replace functionally inactive vessels, and resist the increased wind stress. Although interpretable as giving rise to asymptotic $H: D$ relationships (Sterck et al., 2005), this phenomenon can also be viewed in terms of the allometric scaling coefficient $\left(\beta_{1}\right)$ in Eq. (1) necessarily being less than 1. Indeed, for a vertical basally anchored wooden cylinder with typical wood properties and just thick enough to prevent itself from buckling under its own weight, McMahon (1973) estimated that the relationship $D=0.0011 \mathrm{H}^{1.5}(D$ and $H$ 
both in meters) should apply. This relates to $H=20.2 D^{0.67}$ in the form and units of the current model and from the calculations associated with the pantropical model in Sect 3.1.2 it appears that some trees found at $D=1 \mathrm{dm}$ were approaching heights only just less than their buckling limit and also that some plots have allometric scaling coefficients very close to the theoretical 0.67 maximum (King et al., 2009). Nevertheless, as the slope and intercept of the plot random effect terms were negatively correlated, it seems unlikely for both to occur simultaneously. Rather, it would seem that in plots where trees tend to be close to their buckling limit at $D=1 \mathrm{dm}$ they subsequently grow with allometric scaling coefficients considerably below the theoretical 0.67 limit, thus assuming a greater safety margin as they grow taller. This is not surprising as light competition and hence premium on vertical growth, is most severe at lower levels, while daytime wind speeds, and hence the risk of direct mechanical damage, may increase more-or-less exponentially with canopy height (Kruijt et al., 2000).

Overall, structural and environmental effects on $H: D$ allometry observed were expressed as changes in the intercept rather than in the slope of the log-log models (Tables 2 and 3 ). Since the intercept in our model has a meaningful interpretation (being the natural logarithm of the height of the average tree at $D=1 \mathrm{dm}$ ), this means that effects of environment on forest tree $H$ are already evident at the latesapling stage with the scaling coefficient for all regions, stand structures and environmental conditions below the theoretical buckling limit mentioned above.

\subsection{Vegetation structure effects}

We found stand basal area $(A)$, but not stem density, to be an important driver of variation in $H: D$ allometry. All else being equal, forests with a greater $A$ tended to have taller trees at any given $D$. As high stem densities can occur even in forests with lower stature and lower biomass, the stronger effect of $A$ can probably be explained in terms of greater competition for light imposed by high basal area stands, this necessitating the allocation of more resources to height versus diameter growth, thereby allowing trees to reach the upper layers more rapidly once gaps are formed and to increase their chance of survival. This supports findings from two old-growth forests in Malaysia which have differing $A$ and corresponding different $H: D$ allometry, suggesting a general trend (King et al., 2009). King (1981) also cites data from Ek (1974) showing that widely spaced trees growing in open environments have thicker trunks than those of forest-grown trees of similar height; and, working with a Cordia alliodora plantation spacing trial in Costa Rica, Hummel (2000) found that trees that were more widely spaced tended to have a greater $D$ than those that were more closely packed, but with no effect of stem density on $H$. She interpreted this result in terms of classic plant population biology size-density theory (Yoda et al., 1963) as applied to commercial forestry management operations (Drew and Flewelling, 1977). Here it is considered that trees of a given age will generally all be of a similar height but with a lower average basal area (at any given age/height) when growing in a denser stand due to lower rates of light interception per tree. More densely packed stems may also benefit from wind-sheltering allowing stems to put fewer resources into diameter increment for stability; the effects of light and wind-sheltering are thus difficult to separate (Henry and Aarssen, 1999).

\subsection{Climatic effects}

Results from the pantropical structure environment model provide strong evidence for environmental effects on tree $H: D$ relationships, which persisted even after continental or regional location were taken into account. Precipitation coefficient of variance $\left(P_{\mathrm{V}}\right)$, numbers of months with $<0.1 \mathrm{~m}$ of rainfall $\left(S_{\mathrm{D}}\right)$ and temperature $\left(T_{\mathrm{A}}\right)$ were all highly significant. It should also be noted that altitude $\left(A_{\mathrm{L}}\right)$ and $T_{\mathrm{A}}$ were strongly correlated; inclusion of one of these variables in the model negated the other. In all cases, environment was found to affect the intercept, but not the slope, of the $H: D$ relationship.

\subsubsection{Temporal distribution of rainfall}

Dry-season length emerged as one key factor influencing $H: D$ relationships, with a longer dry season being associated with stouter trees (Tables 2 and 3). The magnitude of this effect can be appreciated from the data underlying Fig. 7b, for which $P_{\mathrm{V}}=0.56$ in all cases (close to the dataset average value), then calculating $\hat{H}$ with $A$ and $T_{\mathrm{A}}$ also at their overall dataset average values. Applying Eq. (13) then for $D=1 \mathrm{dm}$, then we obtain $\hat{H}=13.0 \mathrm{~m}$ for $S_{\mathrm{D}}=3$ months (as for Cavalla, Liberia). On the other hand, for $S_{\mathrm{D}}=9$ months (as for Tucavaca, Bolivia) we estimate for $H$ only $8.9 \mathrm{~m}$. For $D=5 \mathrm{dm}$, there is a difference in $\hat{H}$ of nearly $10 \mathrm{~m}$ with $\hat{H}=20.9 \mathrm{~m}$ versus $30.5 \mathrm{~m}$ for $S_{\mathrm{D}}=9$ versus 3 months, respectively. Dry season length thus exerts a strong effect on tropical forest tree $H: D$ allometry.

Although this effect might be simply interpreted as reduced water availability giving rise to increased hydraulic constraints on potential tree height (Koch et al., 2004; Ryan and Yoder, 1997), the gravitational component of leaf water potential equates to only $0.01 \mathrm{~Pa} \mathrm{~m}^{-1}$, much less than might be expected to be easily offset by compensating physiological processes such as osmotic adjustment (Olivares and Medina, 1992). Likewise, although it could be argued that a longer path-length for water flow for taller trees might necessitate a greater hydraulic resistance and attendant more negative leaf water potentials (thereby limiting maximum tree height when water availability is low), once reasonable assumptions are made about patterns of xylem conduit tapering and packing in stems and branches, it emerges that a greater tree height should not generally be associated with increased hydraulic limitations on productivity or tissue 

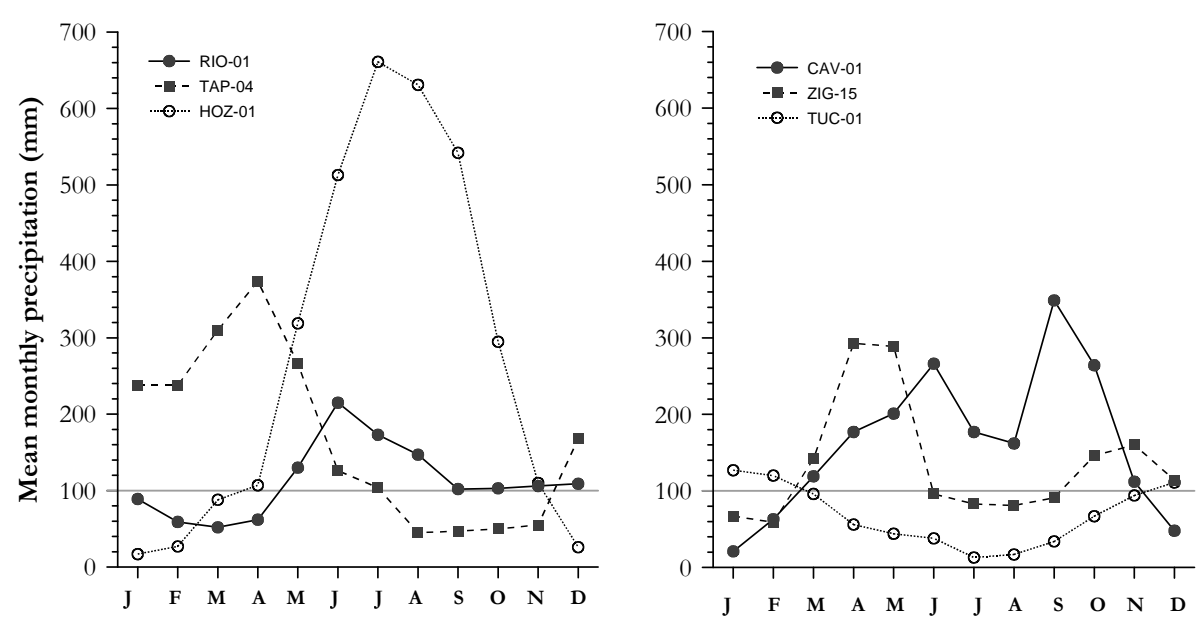

Fig. 7. Precipitation patterns for selected sites showing different patterns associated with dry season length, $S_{\mathrm{D}}$ and precipitation coefficient of variation, $P_{\mathrm{V}}$. (a) variations in, $P_{\mathrm{V}}$ possible with $S_{\mathrm{D}}=4$ months. RIO-01; Rio Grande, Venezuela (Guyanan $\left.S h i e l d\right), P_{\mathrm{V}}=0.41$, mean annual precipitation, $P_{\mathrm{A}}=1.35 \mathrm{~m}$ : TAP-04; Tapajos, Brazil (Central/Eastern Brazil), $P_{\mathrm{V}}=0.65, P_{\mathrm{A}}=2.02$ m, HOZ-01; Chékô, Cambodia, Hozumi (Asia), $P_{\mathrm{V}}=0.86 P_{\mathrm{A}}=3.34 \mathrm{~m}$. (b): observed variations in, $S_{\mathrm{D}}$, but with all sites all having $P_{\mathrm{V}}=0.56$. CVL-01; Cavalla, Liberia (West Africa) $S_{\mathrm{D}}=3$ months, $P_{\mathrm{A}}=1.96 \mathrm{~m}$ : VTA-15; Zigi Forest, Tanzania (East Africa), $S_{\mathrm{D}}=6$ months, $P_{\mathrm{V}}=1.62 \mathrm{~m}$ : TUC-01; Tucavaca, Bolivia (Southern Amazon), $S_{\mathrm{D}}=9$ months, $P_{\mathrm{A}}=0.82 \mathrm{~m}$.

growth per se (Sperry et al., 2008). On the other hand, because trees of the drier semi-deciduous tropical forests are required to maintain some photosynthetic activity during the dry season even in the presence of substantial soil water deficits (e.g., Miranda et al., 2005), greater stem diameters relative to tree height may serve to increase overall rates of water transport due to higher sapwood cross-sectional areas (Meinzer et al., 2001). A greater cross-sectional sapwood area per unit height may also allow for the same hydraulic conductivity with more numerous xylem vessels of a lower diameter than would be the case were the sectional sapwood area less per unit height, this reducing the probablity of cavitation under conditions of high evaporative demand or low water availability (Sperry et al., 2008).

Architectural considerations may also be important in accounting for the dry-season length effect on $H: D$ allometry. This is because tropical tree average tree crown diameters at any given $D$ tend to increase with dry season length (Feldpausch et al., unpublished results). This may allow for increasingly "top-heavy" trees being possible due to the sturdier $H: D$ allometry. All else being equal, this should result in more efficient water flow due to a greater cross-sectional area of xylem vessels existing towards the top of the tree (Sperry et al., 2008).

Somewhat surprisingly, in addition to dry season length, the coefficient of variation for precipitation $\left(P_{\mathrm{V}}\right)$ emerged as a strong predictor for variations in $H: D$ allometry, accounting for more of the observed variation than did annual precipitation. The differential effects of $P_{\mathrm{V}}$ and $S_{\mathrm{D}}$ in modulating the $\log (H): \log (D)$ relationship can be determined by an examination of their likely range and covariability as is shown in
Fig. 7a. This shows, for example, that for our dataset a dry season length of 4 months can be associated with a $P_{\mathrm{V}}$ value ranging from as little as 0.41 (Rio Grande, Venezuela) to as much as 0.86 (Chékô, Cambodia). For simplicity, assuming an overall dataset average $A$ and $T_{\mathrm{A}}\left(32.4 \mathrm{~m}^{2} \mathrm{ha}^{-1}\right.$ and $24.7^{\circ} \mathrm{C}$, respectively) for model simulations these variations in $P_{\mathrm{V}}$ are modeled to give rise to a height difference of $1.9 \mathrm{~m}$ at $D=1 \mathrm{dm}(11.6 \mathrm{~m}$ in Venezuela versus $13.5 \mathrm{~m}$ in Cambodia) with large trees $(D=5 \mathrm{dm})$ typically having even greater differences $(27.1 \mathrm{~m}$ versus $31.6 \mathrm{~m}$, respectively). Opposing the positive effect of a high $P_{\mathrm{V}}$ is a negative effect of dry season length.

Figure 7 also shows that, associated with any given $P_{\mathrm{V}}$, a wide range of $S_{\mathrm{D}}$ may occur and that, generally speaking, a greater $P_{\mathrm{V}}$ at any given dry-season length is associated with a greater amount of wet-season precipitation. This presumably would allow the underlying soil profile to recharge to a greater depth (where possible). On the other hand, a high $P_{\mathrm{V}}$ may, in some circumstances, also be associated with a relatively short dry-season length when the precipitation pattern is bimodal (as for the Liberian site in Fig. 7). This is because, in such situations, the overall variability may be similar to the unimodal case, but with the second smaller "dry season" resulting in less precipitation received of an annual basis (hence a higher $P_{\mathrm{V}}$ ). Associated with this would be expected to be lower runoff losses associated with extreme rainfall events. Bimodal patterns such as that shown for the Cavalla site in Liberia in Fig. 7 are quite common in Western and Equatorial Africa due to interactions between the Intertropical Convergence Zone and the African easterly jets (Hayward and Oguntoyinbo, 1987; Nicholson and Grist, 2003). 


\subsubsection{Temperature and altitude}

The influence of temperature was more modest than for water availability, except when considering higher elevation forests. For example, comparing predictions for the coolest site in our data set (Mazumbai Forest in Tanzania at $1806 \mathrm{~m}$ elevation with $T_{\mathrm{A}}=15.3^{\circ} \mathrm{C}$ ) we obtain $H=10.4 \mathrm{~m}$, and for the hottest site (HOZ-01 in Cambodia $T_{\mathrm{A}}=27.5^{\circ} \mathrm{C}$ ) $H=13.3 \mathrm{~m}$ at $D=1 \mathrm{dm}$ were $A, P_{\mathrm{V}}, S_{\mathrm{D}}$ all at their dataset average values. At $D=5 \mathrm{dm}$ the corresponding estimates for $H$ are 20.9 and $24.5 \mathrm{~m}$, respectively (Fig. 7).

As noted above, much of the variation in $T_{\mathrm{A}}$ observed for this dataset is a consequence of variations in the altitude $\left(A_{\mathrm{L}}\right)$ at which trees were growing. It is well known that trees decrease in average height as altitude increases (Grubb, 1977), this generally being attributed to their lower productivity resulting from persistent cloudiness (low radiation) and a low leaf-area index (Bruijnzeel and Veneklaas, 1998). But this observation per se provides no explanation as to why the $H: D$ allometry itself should change with $T_{\mathrm{A}}$, with trees at higher $A_{\mathrm{L}}$ (lower $T_{\mathrm{A}}$ ) having lower intercepts in the model and hence being shorter at any given $D$.

Following the arguments above, one possibility accounting for this is adverse water relations at higher elevation, for example, due to an increased viscosity of water at lower temperatures (Roderick and Berry, 2001). But there is little to suggest that montane trees are any different from lowland trees in terms of hydraulic construction (Coomes et al., 2007) and, if anything, the available evidence suggests lower likelihood of soil water deficits adversely affecting the function of higher altitude trees (Cavelier, 1990; Zotz et al., 1998; Rada et al., 2009).

It is more likely that structural considerations are important here. Wind speeds generally increase with altitude on mountains (Woodward, 1993) and Lawton (1982) showed that physiognomic differences for Didymopanax pittieri trees growing on a mountain in Costa Rica were related to a gradient of wind stress. Specifically, wind stress in his study forest increased with proximity to ridges and for a given $H$, trunk $D$ increased with proximity to the ridge-crest. This example of thigmorphogenesis (Grace, 1977) has also been observed in experiments manipulating the montane forest seedling wind regime (Cordero, 1999).

There may also be other factors interacting with wind stress to give rise to typically conservative $H: D$ allometries at higher altitudes. For example, soil mineral layers are likely to be thinner, more waterlogged and with generally less favorable conditions for root development (Grieve et al., 1990; Schawe et al., 2007; Quesada et al., 2009a). Although overlying organic layers are often thicker at lower temperatures (Grieve et al., 1990; Wilcke et al., 2008) they are also often structurally fragile, thus providing little mechanical support. This may give rise to the development of extensive but shallow root plates at higher altitude (e.g., Soethe, 2006). Under such circumstances a greater tree stem basal area at the soil level would be expected to provide a more extensive root system that radiates from the trunk before tapering and branching, and thus provide more vertical sinker roots (Ennos, 2000) and greater overall anchorage support. Associated with the greater stem basal area at the soil level would be an attendent reduction in $H: D$ ratios.

\subsection{Geographical location}

Inclusion of continental location or geographical region significantly improved overall model fits as shown by the AIC with regions being the better broad-scale spatial descriptor. From Fig. 3 it is clear that this was mostly due to the Guyana Shield forests having $H: D$ allometries much more similar to African and Asian regions than other parts of South America once environmental effects are taken into account. In that context we note that, unlike most of the rest of Amazonia, the rain forests of the Guyana Shield are characterized by high abundances of caesalpinoids, the most basal members of the legume family, and with similar dominances of the same or closely related genera (e.g., Cynometra, Microberlinia, Tetraberlinia, Gilbertiodendron, Julibernardia) occurring across much of Western and Central Tropical Africa. This unique phytogeographical affinity is likely attributable to the extreme antiquity and stability of the Guyana Shield and a mutual Gondwanan origin for many taxa (Hammond, 2005b). This is much less the case for the rest of the Amazonian forest, especially for areas closer to the Andes which have been subject to recent tectonic uplift. Although, it should be noted that there are also strong phytogeographical affinities between the trees of the Guyana Shield and East/Central Amazonia (Hammond, 2005b).

That Asian trees are the tallest of all regions at higher $D$ (Fig. 3) may be related to the tall stature of the dominant family there, viz. the Dipterocarpaceae: for which some species commonly attain heights of $60 \mathrm{~m}$ (Ashton and Hall, 1992; Yamakura et al., 1986). However, continental differences in the maximum height of tropical forests do not appear to be directly affected by the familial composition of the forests; non-diperterocarps in Asian forests exhibit an equally tall maximum height as diperterocarps and cross-continental differences are still observed within a phylogenetically-constrained subset of the data, the Fabaceae alone (Banin et al. 2011). Futhermore, for a Malaysian forest it has been shown that species which are tall at maximum size tend to be relatively short for a given diameter at juvenile stages (Thomas, 1996). Fabaceae (common in parts of the Guyana Shield and Africa) and Dipterocarpaceae have also been likened to each other in terms of other functional attributes, such as seed size, mast fruiting and juvenile dominance of the understorey, and thus forests dominated by these families may be more similar in terms of allometry (LaFrankie, 2005).

The separation of $H: D$ relationships into two main groups in the region-environment-structure model (Fig. 5b) 
compared to the greater scatter of the region-only model (Fig. 5a) indicates the importance of regional climate and forest structure (i.e. basal area) in directing $H$ development for a given $D$. Here Fig. 5a can be interpreted as showing average $H: D$ relationships actually observed for each region, with Fig. 5b showing what is modelled to occur were all regions to have a similar (average) climates and stand-level basal areas. Thus, although in terms of their "fundamental" allometry Fig. 5b indicates little difference between the three African regions and Asia, Fig. 5a shows that, on average, the forests of Central and East Africa do not reach this "potential". From Table 1 we can conclude this is a consequence of many of the forests sampled there being at higher than average altitudes and hence with a lower $T_{\mathrm{A}}$ and an associated stouter than average stature (Sect. 4.5). On the other hand, Australian forests seem to be more slender than their basic allometry would suggest, this being attributable to higher than average $A$ and $P_{\mathrm{V}}$ more than offsetting the effects of a lower than average $T_{\mathrm{A}}$.

But why, as a whole, should most of the forests of the Amazon and those of Australia be of a different $H: D$ allometry compared to Africa and Asia, even once structural and environmental effects are taken into account? For Australia, it might be argued that a lower stature for a given $D$ might be an adaptation to facilitate survival under catastrophic cyclone events (Webb, 1958) and that such events do not occur in South America (Lonfat et al., 2004) with Caribbean storm tracks rarely crossing the tip of the Guyana Shield countries to Colombia (Hammond, 2005a). Much less frequent but still intense squall lines occasionally can propagate into the interior of Amazonia (Garstang et al., 1998), but destructive effects appear mostly confined to regions of unusually shallow soils and local return times are extremely lengthy (Lloyd et al., 2009a). While a squall event caused extensive damage in Amazonia (Negrón-Juárez et al., 2010), analysis of sequential imagery across the whole region (Espírito-Santo et al., 2010) confirms return times are on the order of tens of thousands of years for any randomly selected patch of forest. Moreover, intense and potentially catastrophic squall lines are also common in the West African tropical forest region (Hayward and Oguntoyinbo, 1987). It would therefore seem that a high probability of extreme wind events cannot explain the stout stature of Amazon forest trees outside the Guyana Shield.

It is also unlikely that large-scale differences in soil fertility underlie the observed differences in $H: D$ allometry (Ashton and Hall, 1992), at least at the regional scale. For example, although it is probably the case that tropical forest soils in Africa and Asia are, on average, more fertile than those of the Amazon Basin (Sanchez, 1976), much of the Congo Basin in Central Africa is characterised by typically infertile ferralsols (Eswaran et al., 1997). Similarly, fertile soils of a relatively recent genesis are quite common in the Western Amazon Basin (Quesada et al., 2009a, 2010).
On the other hand, it may be that Quaternary tectonic and geomorphological processes have played an important role in the observed regional differences in $H: D$ allometry. In particular, it now seems that the rain forests of the Guyana Shield were separated from the rest of the Amazon forest during the Last Glacial Maximum (LGM), with savanna-type vegetation occupying much of what is now the Central and Eastern Amazon forest region (Anhuf et al., 2006). The shrunken Amazon humid forest area was largely confined to the western part of the basin where, as mentioned previously, soils are often quite shallow with more slender trees probably being at a disadvantage due to a greater probability of windthrow. Moreover, as the LGM climate was generally drier, hydraulic constraints may have been more prevalent (perhaps interacting with the generally shallower soils). Moreover, during this, time Western Amazonia was (and remains) a relatively dynamic environment with ongoing tectonic activity and significant lateral erosion and channel changes in meandering rivers and with associated high site turnover disturbance frequencies (Salo et al., 1986). This situation is related to continued uplift of the Andes and presumably favors shorter trees with greater structural stability.

The Brazilian Shield is of similar geological antiquity to the Guyana Shield, though some of the tropical forests there are, by contrast, relatively recent, having expanded southward over the past 3000 years. The present-day limits of these Brazilian-Shield forests represent the southernmost extent of Amazonian rain forest over at least the past 50000 years. This recent rain forest expansion is attributed to increased seasonal latitudinal migration of the Intertropical Convergence Zone (Mayle et al., 2000). Even forests expanding earlier in the Holocene would be expected to have retained the characteristics of the remnant western forests that were able to persist through the LGM.

This situation in South America during and after the LGM would have contrasted with that of S.E. Asia and Africa where tectonic stability has generally been the norm during the Quaternary, with most S.E. Asian forests being located in a tectonically inactive region towards the center of the Sunda plate (Tingay et al., 2010). African forests also occurred in areas considered to have been tectonically stable during the Quaternary (Schlüter, 2008). Moreover, rain forest remnant areas as identified for S.E. Asia and Africa by Heaney (1991) and Anhuf et al. (2006), respectively, seem also to have been mostly in coastal maritime areas where the climate is presumably moister and where deeper soils with fewer structural limitations also prevail (Ashton and Hall, 1992; Eswaran et al., 1997). Thus, in Africa and S.E. Asia there would have been fewer selective pressures towards a less slender growth form that may have increased the probability of survival in the remnant forests. This is in contrast to the Amazon Basin where geological instabilities and marginal soils at the edge of the Andes would have prevailed throughout the remnant forest area, there would have been fewer selective pressures towards a stout stature, thus increasing the probability of 
survival for the more slender growth form in the remnant forests in Africa and S.E. Asia.

It is, however, also the case that many of the soils of Central and Eastern Amazon lowlands are of a considerable depth with few physical limitations (Quesada et al., 2010). At first glance this would provide a more suitable substrate for trees with a Guyanan-type allometry (rather than that of the Western Amazon) according to the above hypothesis. Nevertheless, in the Central and Eastern Amazon regions the dominant soils have an unusually fine texture $(>80 \%$ clay size particles, often "Belterra Clays"; see Quesada et al., 2009a) which, compared to the loamier textured ferralsol type soils of the Guyana Shield (Lescure and Boulet, 1985; Quesada et al., 2010; Van Kekem et al., 1997), have a lower water-holding capacity per unit volume (Hodnett and Tomasella, 2002). These differences in soil-water holding capacity per season would effectively amplify the dry season effect, requiring many East/Central Amazon forests to have deeper rooting depths than would otherwise be the case and could result in greater sapwood cross-sectional areas and associated $H: D$ allometry. Trees in North-West Amazonia die dynamically, while in the North-East they die statically (Chao et al., 2009), which is consistent with the greater structural challenges due to soil constraints in Western Amazonia.

Other possible reasons for differences among regions may be the average successional status of primary forests, biotic interactions affecting forest mechanics, and changing forest structure. For example, there may be regional differences in the extent to which mechanical processes such as branch-fall, partial root tip-up, and bending of stems by liana tree-to-tree links play a role in structuring tree architecture (Hallé et al., 1978). Significant areas of liana forest occur near the southern border of the Amazon on the Brazilian Shield (Daly and Mitchell, 2000). Similarly, forests with a high bamboo abundance are locally prevalent in South-West Amazonia (Daly and Mitchell, 2000; Nelson et al., 2006). Bamboo has a mechanical effect on crown structure as the bending and weight of bamboo shoots break tree branches and crowns (Griscom and Ashton, 2006), tending to reduce tree height for a given diameter. Bamboo may dominate up to $180000 \mathrm{~km}^{2}$ of Amazonian forests (Nelson et al., 2006) and therefore may represent one of several unaccounted factors reducing tree height and carbon stocks at the landscape scale.

Irrespective of the exact reasons for the observed continental differences, the considerable variation in scaling coefficients $\left(\beta_{1}\right)$ observed - from $0.47 \pm 0.02$ for the Brazilian Shield and Western Amazonia to $0.65 \pm 0.03$ for East Africa - argues against the existence of any sort of universal tree scaling allometry as has been argued by some on the basis of tree hydraulics "principles" (Enquist et al., 2000; Niklas and Spatz, 2004). Indeed, the discussions above lend much more strongly towards the notion that variations in $\beta_{1}$ observed are due more to structural as oppossed to hydrological considerations as has also suggested by Taneda and Taneda (2004).

\subsection{Soil phyiscal constraints}

The random plot-effect terms extracted from the final model did not correlate significantly with any measure of soil fertility or texture. However, we found that the Quesada Index of soil physical limitations $(\Pi)$ was related to tree height for trees at $D=1 \mathrm{dm}$; trees growing on soils with few or no physical limitations grew taller than those subject to greater physical limitations (Fig. 6). As was shown by Quesada et al. (2009b), soils with a high $\Pi$ are generally associated with high stand turnover rates due to a higher probability of windthrow or other disturbances (Chao et al., 2009). Consequently, trees on such soils being thicker at any given $H$ could be a structural adaption to increase the probability of survival in the face of adverse soil physical conditions. Alternatively, it may reflect greater light availability in forest stands with higher dynamism, thus reducing the competitive drive to rapidly gain height.

That the relationship between the plot-level residuals and (П) was much stronger for the pantropical-environmentalstructure model than for the regional-environmentalstructure (Fig. 6) also supports the suggestion of Sect. 4.6 that much of the geographic variation in the allometric scaling coefficients observed may be attributable to different susceptibilities to disturbance, either now or in the past. Also of interest, for the regional-environmental-structure model in particular, there was a tendency for the lower outlying plots (i.e., those of unusually stout trees - even after accounting for climate, structure and soil physical characteristics) to be located in forest-savanna transitional areas or even in areas otherwise dominated by savannas. This could be attributable to soils with only modestly constraining soil physical characteristics presenting greater relative constraints on water storage and/or uptake than for precipitation regimes characterised by a shorter dry season (Sect. 4.4) and/or the relationship between $S_{\mathrm{D}}$ and $\beta_{0}$ becoming strongly non-linear as tropical forests trees approach their xeric limits. Nevertheless, there was no relationship between the level-2 (plot) residuals and any of $P_{\mathrm{A}}, P_{\mathrm{V}}$ or $S_{\mathrm{D}}$ (Supplement, Table S3). This lack of any absolute effect of precipitation on the model residuals is perhaps because of transitional forests being located across a wide range of precipitation regimes (with $P_{\mathrm{A}}$ ranging from ca. 0.6 to ca. $1.8 \mathrm{~m} \mathrm{a}^{-1}$ in the current dataset). This large variability in transitional forest precipitation regimes may be due to the tropical vegetation distributions being defined by underlying soil chemical and physical characteristics as well as the more widely recognised climatic constraints (Schimper, 1903; Lloyd et al., 2009b).

\section{Conclusions}

We found tropical tree $H: D$ allometry to be modulated by geographic location, environment and forest structure. Although the precise reasons for these effects remain to be ascertained, we have discussed the likely drivers for 
Table A1. Parameter values for environment-structure to estimate $H(\mathrm{~m})$ from $D$, basal area $\left(A, \mathrm{~m}^{2} \mathrm{ha}^{-1}\right)$, precipitation coefficient of variance $\left(P_{\mathrm{V}}\right)$, dry season $\left(S_{\mathrm{D}}\right.$, no. months $\left.<0.1 \mathrm{~m}\right)$, and mean annual temperature $\left(T_{\mathrm{A}}\right)$, with all variables non-centered (i.e., as measured) and with tree diameters expressed in centimeters denoted as $D^{*}$. All equations are of the form: $\log (H)=\beta_{0}+\beta_{1} \log \left(D^{*}\right)+\varsigma_{01} A+\eta_{01} P_{\mathrm{V}}+$ $\eta_{02} S_{\mathrm{D}}+\eta_{03} T_{\mathrm{A}}$ with all logarithmic terms on the natural (Naperian) scale of base $e$ and $P_{\mathrm{V}}$ in the format reported by the WorldClim dataset (percent).

\begin{tabular}{|c|c|c|c|c|c|c|}
\hline Equation & $\begin{array}{r}\text { Intercept, } \\
\beta_{0}\end{array}$ & $\begin{array}{r}\text { Coefficient of } \\
\log \left(D^{*}\right), \beta_{1}\end{array}$ & $\begin{array}{r}\text { Coefficient of } \\
A, \varsigma_{01}\end{array}$ & $\begin{array}{r}\text { Coefficient of } \\
P_{\mathrm{V}}, \eta_{01}\end{array}$ & $\begin{array}{r}\text { Coefficient of } \\
S_{\mathrm{D}}, \eta_{02}\end{array}$ & $\begin{array}{r}\text { Coefficient of } \\
T_{\mathrm{A}}, \eta_{03}\end{array}$ \\
\hline Pan tropical environment structure & 0.4893 & 0.5296 & 0.0098 & 0.0034 & -0.0632 & 0.0204 \\
\hline Continental-environment-structure (Asia) & 0.3542 & 0.5720 & 0.0121 & 0.0047 & -0.0677 & 0.0157 \\
\hline Continental-environment-structure (Africa) & 0.1789 & 0.6156 & 0.0121 & 0.0047 & -0.0677 & 0.0157 \\
\hline Continental-environment-structure (Australia) & 0.3803 & 0.5161 & 0.0121 & 0.0047 & -0.0677 & 0.0157 \\
\hline Continental-environment-structure (South America) & 0.6722 & 0.4823 & 0.0121 & 0.0047 & -0.0677 & 0.0157 \\
\hline Region-environment-structure (Asia) & 0.2797 & 0.5736 & 0.0120 & 0.0034 & -0.0449 & 0.0191 \\
\hline Region-environment-structure (Central Africa) & 0.3622 & 0.5518 & 0.0120 & 0.0034 & -0.0449 & 0.0191 \\
\hline Region-environment-structure (East Africa) & -0.0984 & 0.6515 & 0.0120 & 0.0034 & -0.0449 & 0.0191 \\
\hline Region-environment-structure (West Africa) & 0.0043 & 0.6362 & 0.0120 & 0.0034 & -0.0449 & 0.0191 \\
\hline Region-environment-structure (Brazilian Shield Amazonia) & 0.6373 & 0.4647 & 0.0120 & 0.0034 & -0.0449 & 0.0191 \\
\hline Region-environment-structure (East-Central Amazonia) & 0.4524 & 0.4936 & 0.0120 & 0.0034 & -0.0449 & 0.0191 \\
\hline Region-environment-structure (Guyana Shield Amazonia) & 0.6429 & 0.5001 & 0.0120 & 0.0034 & -0.0449 & 0.0191 \\
\hline Region-environment-structure (West Amazonia) & 0.6233 & 0.4666 & 0.0120 & 0.0034 & -0.0449 & 0.0191 \\
\hline Region-environment-structure (Australia) & 0.2641 & 0.5171 & 0.0120 & 0.0034 & -0.0449 & 0.0191 \\
\hline
\end{tabular}

these effects and present a new series of field-applicable scale-, environment-, and forest structure-dependent allometric equations to estimate $H$ from $D$ (Appendix A). Due to the variations in $H: D$ allometry observed, we also suggest that $H$ should be included as a parameter in biomass estimates wherever possible. The $H: D$ model equations presented here should, in conjunction with biomass equations that include $H$, permit improved estimates of biomass carbon storage and carbon fluxes across tropical forests.

\section{Appendix A}

\section{Working allometric equations for calculation of tree height from diameter}

Throughout this paper we have used "centered" environmental variables, as these allow for the fitted intercept of the models to be meaningfully interpreted, this being the natural logarithm of the fitted height at $D=1 \mathrm{dm}$ for a tree growing in a stand of average basal area under the average climatic conditions of the dataset. Nevertheless, for working calculations, non-centered parameterizations may be preferable. The two model forms are, however, readily interchangeable. For example, taking the pantropical structure-environment mode we can write

$$
\begin{aligned}
\log (H) & =\gamma_{00}+\varsigma_{01} \tilde{A}+\eta_{01} \tilde{P}_{\mathrm{V}}+\eta_{02} \tilde{S}_{\mathrm{D}} \\
& +\eta_{03} \tilde{T}_{\mathrm{A}}+\gamma_{01} \log (D)
\end{aligned}
$$

where $\tilde{A}$ is the mean centered stand-level basal area, $\tilde{P}_{\mathrm{V}}$ is the mean-centered precipitation coefficient of variation, $\tilde{S}_{\mathrm{D}}$ is the mean-centered dry-season length and $\tilde{T}_{\mathrm{A}}$ is the mean-
Table A2 Parameter values for solely geographically based equations presented in the main text to estimate $H(\mathrm{~m})$ and with tree diameters expressed in centimeters denoted as $D^{*}$. All equations are of the form $\log (H)=\beta_{0}+\beta_{1} \log \left(D^{*}\right)$ with all logarithmic terms on the natural (Naperian) scale of base $e$.

\begin{tabular}{lcc}
\hline & $\begin{array}{c}\text { Intercept, } \\
\beta_{0}\end{array}$ & $\begin{array}{c}\text { Coefficient of } \\
\log \left(D^{*}\right), \beta_{1}\end{array}$ \\
\hline Pan tropical & 1.2229 & 0.5320 \\
\hline Continent (Asia) & 1.2194 & 0.5767 \\
Continent (Africa) & 0.9043 & 0.6170 \\
Continent (Australia) & 1.2113 & 0.5202 \\
Continent (South America) & 1.3760 & 0.4854 \\
\hline Region (Asia) & 1.2156 & 0.5782 \\
Region (Central Africa) & 1.1525 & 0.5547 \\
Region (East Africa) & 0.6757 & 0.6521 \\
Region (West Africa) & 0.8946 & 0.6365 \\
Region (Brazilian Shield Amazonia) & 1.3818 & 0.4651 \\
Region (East-Central Amazonia) & 1.1562 & 0.5072 \\
Region (Guyana Shield Amazonia) & 1.5473 & 0.4985 \\
Region (West Amazonia) & 1.4799 & 0.4669 \\
Region (Australia) & 1.2078 & 0.5214 \\
\hline
\end{tabular}

centered annual average temperature. Equation (A1) can be re-written as

$$
\begin{aligned}
\log (H) & =\gamma_{00}+\varsigma_{01}(A-\bar{A})+\eta_{01}\left(P_{\mathrm{V}}-\bar{P}_{\mathrm{V}}\right) \\
& +\eta_{02}\left(S_{\mathrm{D}}-\bar{S}_{\mathrm{D}}\right)+\eta_{03}\left(T_{\mathrm{A}}-\bar{T}_{\mathrm{A}}\right)+\gamma_{01} \log (D)
\end{aligned}
$$

where $A, P_{\mathrm{V}}, S_{\mathrm{D}}$ and $T_{\mathrm{A}}$ are the (actual) observed values for stand-level basal area, precipitation coefficient of variation (percent), dry-season length and annual average temperature, respectively and $\bar{A}, \bar{P}_{\mathrm{V}}, \bar{S}_{\mathrm{D}}$ and $\bar{T}_{\mathrm{A}}$ are the (overall) dataset 
Table A3 Parameter values for regional-classification-structure equations presented in the main text to estimate $H$ (m) and with tree diameters expressed in centimeters denoted as $D^{*}$. All equations are of the form $\log (H)=\beta_{0}+\beta_{1} \log \left(D^{*}\right)+\varsigma_{01} A$ with all $\operatorname{logarithmic}$ terms on the natural (Naperian) scale of base $e$.

\begin{tabular}{|c|c|c|c|}
\hline Equation & Intercept, $\beta_{0}$ & Coefficient of $\log \left(D^{*}\right), \beta_{1}$ & Coefficient of $A, \varsigma_{01}$ \\
\hline \multicolumn{4}{|l|}{ Dry } \\
\hline Region-classification-structure (Asia) & 0.7565 & 0.5729 & 0.0109 \\
\hline Region-classification-structure (Central Africa) & 0.7172 & 0.5527 & 0.0109 \\
\hline Region-classification-structure (East Africa) & 0.2774 & 0.6514 & 0.0109 \\
\hline Region-classification-structure (West Africa) & 0.4619 & 0.6362 & 0.0109 \\
\hline Region-classification-structure (Brazilian Shield Amazonia) & 1.0436 & 0.4627 & 0.0109 \\
\hline Region-classification-structure (East-Central Amazonia) & 0.8100 & 0.4982 & 0.0109 \\
\hline Region-classification-structure (Guyana Shield Amazonia) & 1.1064 & 0.5002 & 0.0109 \\
\hline Region-classification-structure (West Amazonia) & 1.0301 & 0.4664 & 0.0109 \\
\hline Region-classification-structure (Australia) & 0.6071 & 0.5168 & 0.0109 \\
\hline \multicolumn{4}{|l|}{ Moist } \\
\hline Region-classification-structure (Asia) & 0.9098 & 0.5729 & 0.0109 \\
\hline Region-classification-structure (Central Africa) & 0.8705 & 0.5527 & 0.0109 \\
\hline Region-classification-structure (East Africa) & 0.4307 & 0.6514 & 0.0109 \\
\hline Region-classification-structure (West Africa) & 0.6152 & 0.6362 & 0.0109 \\
\hline Region-classification-structure (Brazilian Shield Amazonia) & 1.1969 & 0.4627 & 0.0109 \\
\hline Region-classification-structure (East-Central Amazonia) & 0.9633 & 0.4982 & 0.0109 \\
\hline Region-classification-structure (Guyana Shield Amazonia) & 1.2597 & 0.5002 & 0.0109 \\
\hline Region-classification-structure (West Amazonia) & 1.1834 & 0.4664 & 0.0109 \\
\hline Region-classification-structure (Australia) & 0.7604 & 0.5168 & 0.0109 \\
\hline \multicolumn{4}{|l|}{ Wet } \\
\hline Region-classification-structure (Asia) & 0.8933 & 0.5729 & 0.0109 \\
\hline Region-classification-structure (Central Africa) & 0.8540 & 0.5527 & 0.0109 \\
\hline Region-classification-structure (East Africa) & 0.4142 & 0.6514 & 0.0109 \\
\hline Region-classification-structure (West Africa) & 0.5987 & 0.6362 & 0.0109 \\
\hline Region-classification-structure (Brazilian Shield Amazonia) & 1.1804 & 0.4627 & 0.0109 \\
\hline Region-classification-structure (East-Central Amazonia) & 0.9468 & 0.4982 & 0.0109 \\
\hline Region-classification-structure (Guyana Shield Amazonia) & 1.2432 & 0.5002 & 0.0109 \\
\hline Region-classification-structure (West Amazonia) & 1.1669 & 0.4664 & 0.0109 \\
\hline Region-classification-structure (Australia) & 0.7439 & 0.5168 & 0.0109 \\
\hline
\end{tabular}

mean values. Rearrangement of Eq. (A2) gives

$$
\begin{aligned}
\log (H) & =\left[\gamma_{00}-\varsigma_{01} \bar{A}-\eta_{01} \bar{P}_{\mathrm{V}}-\eta_{02} \bar{S}_{\mathrm{D}}-\eta_{03} \bar{T}_{\mathrm{A}}\right] \\
& +\varsigma_{01} A+\eta_{01} P_{\mathrm{V}}+\eta_{02} S_{\mathrm{D}}+\eta_{03} T_{\mathrm{A}}+\gamma_{01} \log (D)
\end{aligned}
$$

This shows that the centering of the structural/environmental variables prior to fitting the model does not affect the fitted slopes, only affecting the intercept term (here all the terms within the square brackets). The intercept for non-centered equations can thus readily be recalculated for the centered case and the slopes do not change.

Although the intercept of Eq. (A3) is now intuitively meaningless it is of a form that may be more suitable for working estimations of $H$ from measurements of $D$. Likewise, although we have chosen to express $D$ in units of decimeters throughout this paper (this making the intercept in the centered model the logarithm of the predicted tree height at $D=1 \mathrm{dm}$ - an often used minimum value of $D$ for inclusion of a tree in a forest inventory), most foresters and ecologists prefer to work in centimeters. Retrieval of the "raw" parameters (and those with $D$ in $\mathrm{cm}$ ) from Tables 1 and 2 may prove to be laborious and result in calculations that are subject to error. In order to aid the practical use of the equations presented in this paper, we therefore present the "translated" forms of all model parameterisations in Table A1 (i.e., with all variables non-centered and diameter at breast height expressed in $\mathrm{cm}$ ), with Tables A2 and A3 containing other equations presented in the text tabulated in a readily usable form.

\section{Supplementary material related to this article is available online at: http://www.biogeosciences.net/8/1081/2011/ bg-8-1081-2011-supplement.pdf.}


Acknowledgements. Research was supported by NERC through the Tropical Biomes in Transition (TROBIT) Consortium; AMAZONICA; AfriTRON and the RAINFOR network with additional support from the Gordon and Betty Moore Foundation. LB was supported by a NERC PhD Studentship and Henrietta Hutton Grant (RGS-IBG); SLL was supported by a Royal Society University Research Fellowship; some African data was collected under a NERC New Investigator Award (AfriTRON); Additional support was provided by EScFund grant of the Malaysian Ministry of Science, Technology and Innovation (MOSTI); Tropenbos International and the European Commission (project B7-6201/98-13/FOR); Large-scale Biosphere Atmosphere Experiment in Amazonia (LBA) (ND-11, CD-37, CD-41, and TG-07) under the leadership of the Brazilian Ministry of Science and Technology (MCT); PELD-CNPq and PROCAD-CAPES; and, the Brazilian National Council for Scientific and Technological Development (CNPq). For provision of, or help in collecting data we thank A. W. Graham, M. G. Bradford, A. Ford, D. Wilson, K. Davies, M. Johnson, J. Grace, P. Meir, CSIRO and the Australian Canopy Crane Research Station, James Cook University (Australia), L. Arroyo, E. Chavez, T. Killeen, A. Sota, M. Steininger, J. S. Taborga, (Bolivia); Rohden Indústria Lignea Ltda, J. Barroso, W. Castro, E. Couto, C. A. Passos (deceased), P. Nunes, D. Sasaki, M. Silveira, D.M. de Freitas, G.B. da S. Oliveira, E. C. M. Fernandes, S. Riha, J. Lehmann, I. O. Valério Costa, L. Maracahipes, E. A. Oliveira, H. A. Mews, D. V. Silvério, Instituto de Pesquisa da Amazônia (IPAM), Woods Hole Research Center (WHRC) and Grupo Amaggi at Fazenda Tanguro (Brazil); L. Blanc (French Guiana); J. H. Ovalle, M. M. Solórzano (Peru); R. Sukri, M. Salleh A. B. (Brunei); D. Burslem, C. Maycock (Sabah); L. Chong, S. Davies, R. Shutine, L. K. Kho (Sarawak); for logistical aid and maintenance of the large scale forest dynamics plots at Pasoh Forest Reserve, Malaysia and Lambir Hills National Park, Sarawak, Malaysia, we thank, respectively, the Forest Research Institute Malaysia (FRIM) and the Sarawak Forestry Corporation, Malaysia, the Center for Tropical Forest Science - Arnold Arboretum Asia Program of the Smithsonian Tropical Research Institute and Harvard University, USA and Osaka City University, Japan and their funding agencies; V. O. Sene, J. Sonke, K. C. Nguembou; M.-N. Djuikouo K., R. Fotso and Wildlife Conservation Society, Cameroon, ECOFAC-Cameroon, Cameroon Ministry Scientific Research and Innovation, Cameroon Ministry of Forests and Fauna (MINFOF; Cameroon); A. Moungazi, S. Mbadinga, H. Bourobou, L. N. Banak, T. Nzebi, K. Jeffery, SEGC/CIRMF/WCS Research Station Lopé (Gabon); K. Ntim, K. Opoku, Forestry Commission of Ghana (Ghana); A. K. Daniels, S. Chinekei, J. T. Woods, J. Poker, L. Poorter, Forest Development Authority (Liberia), Valuing the Arc Program, Leverhulme Trust, N. Burgess, A. Balmford, P. K. T. Munishi (Tanzania). This research was only made possible with the enthusiastic help of many field assistants from across Africa, Asia, Australia, and South America, with Shiela Lloyd also providing invaluable assistance with manuscript preperation.

Edited by: R. Duursma

\section{References}

Aiba, S. and Kitayama, K.: Structure, composition and species diversity in an altitude-substrate matrix of rain forest tree communities on Mount Kinabalu, Borneo, Plant Ecol., 140, 139-157, 1999.

Akaike, H.: A new look at the statistical model identification, IEEE T. Automat. Contr., 19, 716-723, 1974.

Anhuf, D., Ledru, M. P., Behling, H., Da Cruz, F. W., Cordeiro, R. C., Van Der Hammen, T., Karmann, I., Marengo, J. A., De Oliveira, P. E., Pessenda, L., Siffedine, A., Albuquerque, A. L., and Dias, P. L. D.: Paleo-environmental change in Amazonian and African rainforest during the LGM, Palaeogeogr. Palaeocl., 239, 510-527, 2006.

Ashton, P. S. and Hall, P.: Comparisons of structure among mixed dipterocarp forests of North-Western Borneo, J. Ecol., 80, 459481, 1992.

Bailey, R.: The potential of Weibull-type functions as flexible growth curves: discussion, Can. J. Forest Res., 10, 117-118, 1980.

Baker, T. R., Phillips, O. L., Malhi, Y., Almeida, S., Arroyo, L., Di Fiore, A., Erwin, T., Higuchi, N., Killeen, T. J., Laurance, S. G., Laurance, W. F., Lewis, S. L., Monteagudo, A., Neill, D. A., Vargas, P. N., Pitman, N. C. A., Silva, J. N. M., and Martinez, R. V.: Increasing biomass in Amazonian forest plots, Phil. Trans. Roy. Soc. Lond. B, 359, 353-365, 2004a.

Baker, T. R., Phillips, O. L., Malhi, Y., Almeida, S., Arroyo, L., Di Fiore, A., Erwin, T., Killeen, T. J., Laurance, S. G., Laurance, W. F., Lewis, S. L., Lloyd, J., Monteagudo, A., Neill, D. A., Patino, S., Pitman, N. C. A., Silva, J. N. M., and Martinez, R. V.: Variation in wood density determines spatial patterns in Amazonian forest biomass, Glob. Change Biol., 10, 545-562, 2004b.

Baker, T. R., Phillips, O. L., Laurance, W. F., Pitman, N. C. A., Almeida, S., Arroyo, L., DiFiore, A., Erwin, T., Higuchi, N., Killeen, T. J., Laurance, S. G., Nascimento, H., Monteagudo, A., Neill, D. A., Silva, J. N. M., Malhi, Y., López Gonzalez, G., Peacock, J., Quesada, C. A., Lewis, S. L., and Lloyd, J.: Do species traits determine patterns of wood production in Amazonian forests?, Biogeosciences, 6, 297-307, doi:10.5194/bg-6297-2009, 2009.

Banin, L.: Cross-continental comparisons of tropical forest structure and function, $\mathrm{PhD}$, School of Geography, $\mathrm{PhD}$ Thesis. University of Leeds, Leeds, 2010.

Banin, L., Feldpausch, T. R., Phillips, O. L., Baker, T. R., Lloyd, J., Affum-Baffoe, K., Arets, E. J. M. M., Bradford, M., Berry, N. J., Drescher, M., Lopez-Gonzalez, G., Higuchi, N., Hilbert, D., Hladik, A., Iida, Y., Salim, K. A., Kassim, A. R., King, D. A., Metcalfe, Nilus, R., Peh, K. S-H., Reitsma, J. M., Sonké, B., Taedoumg, H., Tan, S., White, L., Wöll, H., and Lewis, S. L., Cross-continental comparisons of maximum tree height and allometry: testing environmental, structural and floristic drivers, Global Ecology and Biogeography, in review, 2011.

Brown, S., Gillespie, A. J. R., and Lugo, A. E.: Biomass estimation methods for tropical forests with applications to forestry inventory data, Forest Sci., 35, 881-902, 1989.

Bruijnzeel, L. A. and Veneklaas, E. J.: Climatic conditions and tropical, montane forest productivity: the fog has not lifted yet, Ecology, 79, 3-9, 1998.

Bullock, S. H.: Developmental patterns of tree dimensions in 
a neotropical deciduous forest, Biotropica, 32, 42-52, 2000.

Cavelier, J.: Tissue water relations in elfin cloud forest tree species of Serrania de Macuira, Guajira, Colombia, Trees-Struct. Funct., 4, 155-163, 1990.

Chambers, J. Q., Dos Santos, J., Ribeiro, R. J., and Higuchi, N.: Tree damage, allometric relationships, and above-ground net primary production in Central Amazon forest, Forest Ecol. Manag., 152, 73-84, 2001.

Chao, K.-J., Phillips, O. L., Baker, T. R., Peacock, J., LopezGonzalez, G., Vásquez Martínez, R., Monteagudo, A., and Torres-Lezama, A.: After trees die: quantities and determinants of necromass across Amazonia, Biogeosciences, 6, 1615-1626, doi:10.5194/bg-6-1615-2009, 2009.

Chave, J., Andalo, C., Brown, S., Cairns, M. A., Chambers, J. Q., Eamus, D., Folster, H., Fromard, F., Higuchi, N., Kira, T., Lescure, J. P., Nelson, B. W., Ogawa, H., Puig, H., Riera, B., and Yamakura, T.: Tree allometry and improved estimation of carbon stocks and balance in tropical forests, Oecologia, 145, 8799, 2005.

Coomes, D. A., Jenkins, K. L., and Cole, L. E. S.: Scaling of tree vascular transport systems along gradients of nutrient supply and altitude, Biol. Lett., 3, 86-89, 2007.

Cordero, R. A.: Ecophysiology of Cecropia schreberiana saplings in two wind regimes in an elfin cloud forest: growth, gas exchange, architecture and stem biomechanics, Tree Physiol., 19, 153-163, 1999.

Daly, D. C. and Mitchell, J. D.: Lowland vegetation of tropical South America - an overview, in: Imperfect Balance: Landscape Transformations in the pre-Columbian Americas, edited by: Lentz, D., Columbia University Press, New York, 391-454, 2000.

de Gouvenain, R. C. D. and Silander, J. A.: Do tropical storm regimes influence the structure of tropical lowland rain forests? Biotropica, 35, 166-180, 2003.

Drew, T. J. and Flewelling, J. W.: Some recent Japanese theories of yield-density relationships and their application to Monterey pine plantations, Forest Sci., 23, 517-534, 1977.

Ek, A. R.: Dimensional relationships of forest and open grown trees in Wisconsin, University of Wisconsin Forestry Research Note $181,1974$.

Ennos, A. R.: The Mechanics of Root Anchorage, Advances in Botanical Research Incorporating Advances in Plant Pathology, vol. 33, Academic Press Ltd., London, 133-157, 2000.

Enquist, B. J., West, G. B., and Brown, J. H.: Quarter-power allometric scaling in vascular-plants: functional basis and ecological consequences, in: Scaling in Biology, edited by: Brown, J. H. and West, G. B., Oxford University Press, Oxford, UK, 167-198, 2004.

Espírito-Santo, F. D. B., Keller, M., Braswell, B., Nelson, B. W., Frolking, S., and Vicente, G.: Storm intensity and old-growth forest disturbances in the Amazon region, Geophys. Res. Lett., 37, L11403-L11403, 2010.

Eswaran, H., Almaraz, R., Vandenberg, E., and Reich, P.: An assessment of the soil resources of Africa in relation to productivity, Geoderma, 77, 1-18, 1997.

Fang, Z. and Bailey, R. L.: Height-diameter models for tropical forests on Hainan Island in Southern China, Forest Ecol. Manag., 110, 315-327, 1998.

Fensham, R. J.: Floristics and environmental relations of inland dry rainforest in North Queensland, Australia, J. Biogeogr., 22, 1047-106, 1996.

Garstang, M., White, S., Shugart, H. H., and Halverson, J.: Convective cloud downdrafts as the cause of large blowdowns in the Amazon rainforest, Meteorol. Atmos. Phys., 67, 199-212, 1998.

Gee, G. W. and Bauder, J. W.: Particle-size analysis. Methods in soil analysis, Part 1. Physical and mineralogical methods, edited by: Klute, A., SSSA and ASA, Madison, Wisconsin, USA, 383-409, 1986.

Giraudoux, P.: pgirmess: Data analysis in ecology, R package version 1.4.5., http://CRAN.R-project.org/package=pgirmess.

Grace, J.: Plant Response to Wind, Academic Press, London, 1977.

Graham, A. W.: The CSIRO Rainforest Permanent Plots of North Queensland: Site, Structural, Floristic and Edaphic Descriptions, Rainforest CRC, James Cook University, Cairns, Australia, 227 pp., 2006.

Grieve, I. C., Proctor, J., and Cousins, S. A.: Soil variation with altitude on Volcan Barva, Costa Rica, Catena, 17, 525-534, 1990.

Griscom, B. W. and Ashton, P. M. S.: A self-perpetuating bamboo disturbance cycle in a neotropical forest, J. Trop. Ecol., 22, 587597, 2006

Grubb, P. J.: Control of forest growth and distribution on wet tropical mountains: with special reference to mineral nutrition, Annu. Rev. Ecol. Syst., 8, 83-107, 1977.

Hallé, F., Oldemann, R. A. A., and Tomlinson, P. B.: Tropical Trees and Forests: An Architectural Analysis, Springer-Verlag, Berlin, 1978.

Hammond, D. S.: Biophysical features of the Guianan Shield. Tropical Forests of the Guinea Shield. Ancient Forests in a Modern World, edited by: Hammond, D. S., CABI, Wallingford, UK, 15-194, 2005a.

Hammond, D. S.: Guianan forest dynamics: geomorphological control and tropical forest change across diverging landscapes, in: Tropical Forests of the Guiana Shield: Ancient Forests in a Modern World, edited by: Hammond, D. S., CABI Publishing, Wallingford, UK, 343-379, 2005b.

Hayward, D. F. and Oguntoyinbo, J. S.: The Climatology of West Africa, Hutchinson, London, 1987.

Heaney, L. R.: A synopsis of climatic and vegetational change in Southeast Asia, Climatic Change, 19, 53-61, 1991.

Henry, H. A. L. and Aarssen, L. W.: The interpretation of stem diameter-height allometry in trees: biomechanical constraints, neighbour effects, or biased regressions? Ecol. Lett., 2, 89-97, 1999.

Hijmans, R. J., Cameron, S. E., Parra, J. L., Jones, P. G., and Jarvis, A.: Very high resolution interpolated climate surfaces for global land areas, Int. J. Climatol., 25, 1965-1978, 2005.

Hodnett, M. G. and Tomasella, J.: Marked differences between van Genuchten soil water-retention parameters for temperate and tropical soils: a new water-retention pedo-transfer functions developed for tropical soils, Geoderma, 108, 155-180, 2002.

Holdridge, L.: Life Zone Ecology, Tropical Science Center, San Jose, Costa Rica, 206 pp., 1967.

Hozumi, K., Yoda, K., Kokawa, S., and Kira, T.: Production ecology of tropical rain forests in Southwestern Cambodia, I. Plant Biomass., Nature and Life in Southeast Asia, 6, 1969.

Hummel, S.: Height, diameter and crown dimensions of Cordia alliodora associated with tree density, Forest Ecol. Manag., 127, 31-40, 2000. 
Iida, Y., Kohyama, T. S., Kubo, T., Kassim, A. R., Poorter, L., Sterck, F., and Potts, M. D.: Tree architecture and life-history strategies across 200 co-occurring tropical tree species, Funct. Ecol., in review, 2011.

Ketterings, Q. M., Coe, R., Van Noordwijk, M., Ambagau, Y., and Palm, C. A.: Reducing uncertainty in the use of allometric biomass equations for predicting above-ground tree biomass in mixed secondary forests, Forest Ecol. Manag., 146, 199-209, 2001.

King, D.: Tree dimensions: maximizing the rate of height growth in dense stands, Oecologia, 51, 351-356, 1981.

King, D. A.: The adaptive significance of tree height, Am. Nat., 135, 809-828, 1990.

King, D. A.: Allometry and life history of tropical trees, J. Trop. Ecol., 12, 25-44, 1996.

King, D. A., Davies, S. J., Tan, S., and Noor, N. S. M.: Trees approach gravitational limits to height in tall lowland forests of Malaysia, Funct. Ecol., 23, 284-291, 2009.

Kira, T.: Community architecture and organic matter dynamics in tropical lowland rain forests of Southeast Asia with special reference to Pasoh forest, West Malaysia, in: Tropical Trees as Living Systems, edited by: Tomlinson, P. B. and Zimmermann, M. F., Cambridge Univ. Press, Cambridge, 561-590, 1978.

Koch, G. W., Sillett, S. C., Jennings, G. M., and Davis, S. D.: The limits to tree height, Nature, 428, 851-854, 2004.

Kohyama, T., Suzuki, E., Partomihardjo, T., Yamada, T., and Kubo, T.: Tree species differentiation in growth, recruitment and allometry in relation to maximum height in a Bornean mixed dipterocarp forest, J. Ecol., 91, 797-806, 2003.

Kruijt, B., Malhi, Y., Lloyd, J., Norbre, A. D., Miranda, A. C., Pereira, M. G. P., Culf, A., and Grace, J.: Turbulence statistics above and within two Amazon rain forest canopies, Bound-Lay. Meteorol., 94, 297-331, 2000.

Lawton, R. O.: Wind stress and elfin stature in a montane rain forest tree: an adaptive explanation, Am. J. Bot., 69, 1224-1230, 1982.

LaFrankie, J.: Lowland tropical rain forests of Asia and America: parallels, convergence, and divergence, in: Pollination Ecology and the Rain Forest, edited by: Roubik, D. W., Sakai, S., and Hamid Karim, A. A., Ecological Studies, Springer, New York, 178-190, 2005.

Lescure, J. P. and Boulet, R.: Relationships between soil and vegetation in a tropical rain forest in French Guiana, Biotropica, 17, 155-164, 1985.

Lewis, S. L., López-González, G., Sonké, B., Affum-Baffoe, K., Baker, T. R., Ojo, L. O., Phillips, O. L., Reitsma, J. M., White, L., Comiskey, J. A., Djuikouo K., M.-N., Ewango, C. E. N., Feldpausch, T. R., Hamilton, A. C., Gloor, M., Hart, T., Hladik, A., Lloyd, J., Lovett, J. C., Makana, J.-R., Malhi, Y., Mbago, F. M., Ndangalasi, H. J., Peacock, J., Peh, K. S. H., Sheil, D., Sunderland, T., Swaine, M. D., Taplin, J., Taylor, D., Thomas, S. C., Votere, R., and Woll, H.: Increasing carbon storage in intact african tropical forests, Nature, 457, 1003-1006, 2009.

Lieberman, D., Milton, L., Peralta, R., and Hartshorn, G. S.: Tropical forest structure and composition on a large-scale altitudinal gradient in Costa Rica, J. Ecol., 84, 137-152, 1996.

Lloyd, J., Gloor, E. U., and Lewis, S. L.: Are the dynamics of tropical forests dominated by large and rare disturbance events? Ecol. Lett., 12, E19-E21, 2009a.

Lloyd J., Goulden, M., Ometto, J. P., Fyllas, N. M., Quesada, C. A., and Patiño, S.: Ecophysiology of forest and savanna vegetation, in: Amazonia and Climate Change, edited by: Keller, M., Gash, J., and Silva Dias, P., American Geophysical Union, Washington DC, 463-484, 2009b.

Lloyd, J., Patiño, S., Paiva, R. Q., Nardoto, G. B., Quesada, C. A., Santos, A. J. B., Baker, T. R., Brand, W. A., Hilke, I., Gielmann, H., Raessler, M., Luizão, F. J., Martinelli, L. A., and Mercado, L. M.: Optimisation of photosynthetic carbon gain and within-canopy gradients of associated foliar traits for Amazon forest trees, Biogeosciences, 7, 1833-1859, doi:10.5194/bg-71833-2010, 2010.

Lonfat, M., Marks, F. D., and Chen, S. Y. S.: Precipitation distribution in tropical cyclones using the Tropical Rainfall Measuring Mission (TRMM) microwave imager: a global perspective, Mon. Weather Rev., 132, 1645-1660, 2004.

Malhi, Y., Baker, T. R., Phillips, O. L., Almeida, S., Alvarez, E., Arroyo, L., Chave, J., Czimczik, C. I., Di Fiore, A., Higuchi, N., Killeen, T. J., Laurance, S. G., Laurance, W. F., Lewis, S. L., Montoya, L. M. M., Monteagudo, A., Neill, D. A., Vargas, P. N., Patino, S., Pitman, N. C. A., Quesada, C. A., Salomao, R., Silva, J. N. M., Lezama, A. T., Martinez, R. V., Terborgh, J., Vinceti, B., and Lloyd, J.: The above-ground coarse wood productivity of 104 Neotropical forest plots, Glob. Change Biol., 10, 563-591, 2004.

Malhi, Y., Wood, D., Baker, T. R., Wright, J., Phillips, O. L., Cochrane, T., Meir, P., Chave, J., Almeida, S., Arroyo, L., Higuchi, N., Killeen, T. J., Laurance, S. G., Laurance, W. F., Lewis, S. L., Monteagudo, A., Neill, D. A., Vargas, P. N., Pitman, N. C. A., Quesada, C. A., Salomao, R., Silva, J. N. M., Lezama, A. T., Terborgh, J., Martinez, R. V., and Vinceti, B.: The regional variation of aboveground live biomass in old-growth Amazonian forests, Glob. Change Biol., 12, 1107-1138, 2006.

Malhi, Y. and Wright, J.: Spatial patterns and recent trends in the climate of tropical rainforest regions, Phil. Trans. R. Soc. Lond. B., 359, 311-329, 2004.

Mayle, F. E., Burbridge, R., and Killeen, T. J.: Millennial-scale dynamics of Southern Amazonian rain forests, Science, 290, 22912294, 2000.

McKean, J. W., Terpstra, J. T., and Kloke, J. D.: Computational rank-based statistics, WIREs Comput. Stat., 1, 132-140, 2009.

McMahon, T.: Size and shape in biology: elastic criteria impose limits on biological proportions, and consequently on metabolic rates, Science, 179, 1201-1204, 1973.

Meinzer, F. C., Goldstein, G., and Andrade, J. L.: Regulation of water flux through tropical forest canopy trees: do universal rules apply? Tree Physiol., 21, 19-26, 2001.

Miranda, E. J., Vourlitis, G. L., Priante, N., Priante, P. C., Campelo, J. H., Suli, G. S., Fritzen, C. L., Lobo, F. D. A., and Shiraiwa, S.: Seasonal variation in the leaf gas exchange of tropical forest trees in the rain forest-savanna transition of the Southern Amazon Basin, J. Trop. Ecol., 21, 451-460, 2005.

Moles, A. T., Warton, D. I., Warman, L., Swenson, N. G., Laffan, S. W., Zanne, A. E., Pitman, A., Hemmings, F. A., and Leishman, M. R.: Global patterns in plant height, J. Ecol., 97, 923-932, doi:10.1111/j.1365-2745.2009.01526.x, 2009.

Müller, D. and Nielsen, J.: Production brute, pertes par respiration et production nette dans la forêt ombrophile tropicale, Det Forstlige Forsgsvaesen i Danmark, 29, 69-160, 1965.

Nascimento, H. E. M. and Laurance, W. F.: Total aboveground 
biomass in Central Amazonian rainforests: a landscape-scale study, Forest Ecol. Manag., 168, 311-321, 2002.

Neal, G. D.: Statistical Description of the Forests of Thailand, Military Research and Development Center, Bangkok, 1967.

Negrón-Juárez, R. I., Chambers, J. Q., Guimaraes, G., Zeng, H., Raupp, C. F. M., Marra, D. M., Ribeiro, G. H. P. M., Saatchi, S. S., Nelson, B. W., and Higuchi, N.: Widespread Amazon forest tree mortality from a single cross-basin squall line event, Geophys. Res. Lett., 37, L16701, doi:10.1029/2010GL043733, 2010.

Nelson, B. W., Oliveira, Á. C. D., Vidalenc, D., and Smith, M.: Florestas dominadas por tabocas semi-escandentes do gênero Guadua, no sudoeste da Amazônia. Seminário Nacional de Bambu: estruturação da rede de pesquisa e desenvolvimento, edited by: Almeida, J. G. D. and Teixeira, A. A., Brasília, Brazil, 49-55, 2006.

Nelson, D. W. and Sommers, L. E.: Total Carbon and Total Nitrogen. Methods of Soil Analysis: Part 3 - Chemical Methods, SSSA Book Series No 5, edited by: Sparks, D. L., SSSA and ASA, Madison, 961-1010, 1996.

Nicholson, S. E. and Grist, J. P.: The seasonal evolution of the atmospheric circulation over West Africa and equatorial Africa, J. Climate, 16, 1013-1030, 2003.

Niklas, K. J. and Spatz, H.-C.: Growth and hydraulic (not mechanical) constraints govern the scaling of tree height and mass, Proc. Natl. Acad. Sci. USA, 101, 15661-15663, 2004.

Nogueira, E. M., Fearnside, P. M., Nelson, B. W., Barbosa, R. I., and Keizer, E. W. H.: Estimates of forest biomass in the Brazilian Amazon: new allometric equations and adjustments to biomass from wood-volume inventories, Forest Ecol. Manag., 256, 18531867, 2008a.

Nogueira, E. M., Nelson, B. W., Fearnside, P. M., França, M. B., and Oliveira, Á. C. A. D.: Tree height in Brazil's "arc of deforestation": shorter trees in South and Southwest Amazonia imply lower biomass, Forest Ecol. Manag., 255, 2963-2972, 2008b.

O'Brien, S. T., Hubbell, S. P., Spiro, P., Condit, R., and Foster, R. B.: Diameter, height, crown, and age relationship in eight neotropical tree species, Ecology, 76, 1926-1939, 1995.

Ogawa, H., Yoda, K., and Kira, T.: Comparative ecological studies on three main types of forest vegetation in Thailand: II. Plant biomass, Nature and Life in South East Asia, 4, 49-80, 1965.

Ogino, K., Ratanawongs, D., Tsutsumi, T., and Shidei, T.: The primary productivity of tropical forests in Thailand, Southeast Asian Studies, 5, 121-154, 1967.

Olivares, E. and Medina, E.: Water and nutrient relations of woody perennials from tropical dry forests, J. Veg. Sci., 3, 383-392, 1992.

Osunkoya, O. O., Omar-Ali, K., Amit, N., Dayan, J., Daud, D. S., and Sheng, T. K.: Comparative height crown allometry and mechanical design in 22 tree species of Kuala Belalong rainforest, Brunei, Borneo, Am. J. Bot., 94, 1951-1962, 2007.

Paoli, G., Curran, L., and Slik, J.: Soil nutrients affect spatial patterns of aboveground biomass and emergent tree density in Southwestern Borneo, Oecologia, 155, 287-299, doi:10.1007/s00442-007-0906-9, 2008.

Pella, E.: Elemental organic analysis, Part 2. State of the art, Am. Lab., 22, 28-32, 1990.

Phillips, O. L., Aragão, L. E. O. C., Lewis, S. L., Fisher, J. B., Lloyd, J., López-Gonzáles, G., Malhi, Y., Monteagudo, A.,
Peacock, J., Quesada, C. A., Heijden, G. Van Der, Almeida, S., Amaral, I., Arroyo, L., Aymard, G., Baker, T. R., Bánki, O., Blanc, L., Bonal, D., Brando, P., Chave, J., Oliveira, Ã. C. A., Cardozo, N. D., Czimczik, C. I., Feldpausch, T. R., Freitas, M. A., Gloor, E., Higuchi, N., Jiménez, E., Lloyd, G., Meir, P., Mendoza, C., Morel, A., Neill, D. A., Nepstad, D., Patiño, S., Penuela, M.C., Prieto, A., Ramirez, F., Schwarz, M., Silva, J., Silveira, M., Thomas, A.S., Steege, H. Ter, Stropp, J., Váasquez, R., Zelazowski, P., Dávila, E. A., Andelman, S., Andrade, A., Chao, K.-J., Erwin, T., Fiore, A. Di, Keeling, H., Killeen, T. J., Laurance, W. F., Cruz, A. P., Pitman, N. C. A., Vargas, P. N., Ramírez-Angulo, H., Rudas, A., Salamão, R., Silva, N., Terborgh, J., Torres-Lezama, A.: Drought sensitivity of the Amazon rainforest. Science 323: 1344-1347, 2009.

Phillips, O. L., Baker, T. R., Brienen, R., and Feldpausch, T. R.: Field manual for Plot Establishment and Remeasurement, available at: www.geog.leeds.ac.uk/projects/rainfor/pages/manuals_ eng.html/, 2010.

Phillips, O.L., Lewis, S.L., Baker, T.R., Chao, K.-J., Higuchi, N.: The changing Amazon forest. Philosophical Transactions of the Royal Society, Ser.B. 363: 1819-1828, 2008.

Phillips, O. L., Malhi, Y., Higuchi, N., Laurance, W. F., Nunez, P. V., Vasquez, R. M., Laurance, S. G., Ferreira, L. V., Stern, M., Brown, S., and Grace, J.: Changes in the carbon balance of tropical forests: evidence from long-term plots, Science, 282, 439442, 1998.

Pinheiro, J., Bates, D., DebRoy, S., Sarkar, D., and the R Development Core Team: nlme: Linear and Nonlinear Mixed Effects Models. R package version 3.1-97, 2010.

Pleysier, J. L. and Juo, A. S. R.: A single-extraction method using silver-thiourea for measuring exchangeable cations and effective CEC in soils with variable charges, Soil Sci., 129, 205-211, 1980.

Poorter, L., Bongers, F., Sterck, F. J., and Woll, H.: Architecture of 53 rain forest tree species differing in adult stature and shade tolerance, Ecology, 84, 602-608, 2003.

Poorter, L., Bongers, L., and Bongers, F.: Architecture of 54 moistforest tree species: traits, trade-offs, and functional groups, Ecology, 87, 1289-1301, 2006.

Proctor, J., Anderson, J. M., Fogden, S. C. L., and Vallack, H. W.: Ecological studies in four contrasting lowland rain forests in $\mathrm{Gu}-$ nung Mulu National Park, Sarawak: II. Litterfall, litter standing crop and preliminary observations in herbivory, J. Ecol., 71, 261283, 1983.

Quesada, C. A., Lloyd, J., Anderson, L. O., Fyllas, N. M., Schwarz, M., and Czimczik, C. I.: Soils of amazonia with particular reference to the rainfor sites, Biogeosciences Discuss., 6, 3851-3921, doi:10.5194/bgd-6-3851-2009, 2009a.

Quesada, C. A., Lloyd, J., Schwarz, M., Baker, T. R., Phillips, O. L., Patiño, S., Czimczik, C., Hodnett, M. G., Herrera, R., Arneth, A., Lloyd, G., Malhi, Y., Dezzeo, N., Luizão, F. J., Santos, A. J. B., Schmerler, J., Arroyo, L., Silveira, M., Priante Filho, N., Jimenez, E. M., Paiva, R., Vieira, I., Neill, D. A., Silva, N., Peñuela, M. C., Monteagudo, A., Vásquez, R., Prieto, A., Rudas, A., Almeida, S., Higuchi, N., Lezama, A. T., López-González, G., Peacock, J., Fyllas, N. M., Alvarez Dávila, E., Erwin, T., di Fiore, A., Chao, K. J., Honorio, E., Killeen, T., Peña Cruz, A., Pitman, N., Núñez Vargas, P., Salomão, R., Terborgh, J., and Ramírez, H.: Regional and large-scale patterns in Amazon forest 
structure and function are mediated by variations in soil physical and chemical properties, Biogeosciences Discuss., 6, 39934057, doi:10.5194/bgd-6-3993-2009, 2009b.

Quesada, C. A., Lloyd, J., Schwarz, M., Patiño, S., Baker, T. R., Czimczik, C., Fyllas, N. M., Martinelli, L., Nardoto, G. B., Schmerler, J., Santos, A. J. B., Hodnett, M. G., Herrera, R., Luizão, F. J., Arneth, A., Lloyd, G., Dezzeo, N., Hilke, I., Kuhlmann, I., Raessler, M., Brand, W. A., Geilmann, H., Moraes Filho, J. O., Carvalho, F. P., Araujo Filho, R. N., Chaves, J. E., Cruz Junior, O. F., Pimentel, T. P., and Paiva, R.: Variations in chemical and physical properties of Amazon forest soils in relation to their genesis, Biogeosciences, 7, 1515-1541, doi:10.5194/bg-7-15152010, 2010.

R Development Core Team.: R: A language and environment for statistical computing. R Foundation for Statistical Computing, Vienna, Austria, 2009, available at: http://www.R-project.org.

Rada, F., Garcia-Nuñez, C., and Ataroff, M.: Leaf gas exchange in canopy species of a Venezuelan cloud forest, Biotropica, 41, 659-664, 2009.

Roderick, M. L. and Berry, S. L.: Linking wood density with tree growth and environment: a theoretical analysis based on the motion of water, New Phytol., 149, 473-485, 2001.

Ryan, M. G., Phillips, N., and Bond, B. J.: The hydraulic limitation hypothesis revisited, Plant Cell Environ., 29, 267-281, 2006.

Ryan, M. G., and Yoder, B. J.: Hydraulic limits to tree height and tree growth., Bioscience, 47, 235-242, 1997.

Sabhasri, S., Khemnark, C., Aksornkoae, S., and Ratisoonthorn, P.: Primary production in dry-evergreen forest at Sakaerat, Amphoe Pak Thong Chai, Changwat Nakhon Ratchasima. I. Estimation of biomass and distribution amongst various organs, ASRCT, Bangkok, 38 pp., 1968.

Salo, J., Kalliola, R., Hakkinen, I., Makinen, Y., Niemela, P., Puhakka, M., and Coley, P. D.: River dynamics and the diversity of Amazon lowland forest, Nature, 322, 254-258, 1986.

Sanchez, P. A.: Properties and Management of Soils in the Tropics, Wiley, New York, 1976.

Schawe, M., Glatzel, S., and Gerold, G.: Soil development along an altitudinal transect in a Bolivian tropical montane rainforest: Podzolization vs. hydromorphy, Catena, 69, 83-90, 2007.

Schimper, A. F. W.: Plant Geography upon a physiological basis, translated from the German by Fisher, W. R., Clarendon Press, Oxford, 1903.

Schlüter, T.: Geological Atlas of Africa, 2nd edn., Springer-Verlag, Berlin, 2008.

Shuttleworth, W. J.: Evaporation from Amazonian rainforest, P. Roy. Soc. Lond. B Bio., 233, 321-346, 1988.

Snijders, T. A. B. and Bosker, R. J.: Multilevel Analysis: An Introduction to Basic and Advanced Multilevel Modelling, Sage Publications, London, 1999.
Soethe, N., Lehmann, J., and Engels, C.: Root morphology and anchorage of six native tree species from a tropical montane forest and an elfin forest in Ecuador, Plant Soil, 279, 173-185, 2006.

Sperry, J. S., Meinzer, F. C., and Mcculloh, K. A.: Safety and efficiency conflicts in hydraulic architecture: scaling from tissues to trees, Plant Cell Environ., 31, 632-645, 2008.

Sterck, F. J. and Bongers, F.: Crown development in tropical rain forest trees: patterns with tree height and light availability, J. Ecol., 89, 1-13, 2001.

Sterck, F. J., Schieving, F., Lemmens, A., and Pons, T. L.: Performance of trees in forest canopies: explorations with a bottomup functional-structural plant growth model, New Phytol., 166, 827-843, 2005.

Taneda, H. and Taneda, M.: The criteria for biomass partitioning of the current shoot: water transport versus mechanical support, Am. J. Bot., 91, 1941-1500, 2004.

Terpstra, J. T. and McKean, J. W.: Rank-based analysis of linear models using R, J. Stat. Softw., 14, 7, 2005.

Thomas, S. C.: Asymptotic height as a predictor of growth and allometric characteristics in Malaysian rain forest trees, Am. J. Bot., 83, 556-566, 1996.

Thomas, S. C. and Bazzaz, F. A.: Asymptotic height as a predictor of photosynthetic characteristics in Malaysian forest trees, Ecology, 80, 1607-1622, 1999.

Tingay, M., Morley, C., King, R., Hillis, R., Coblentz, D., and Hall, R.: Present-day stress field of Southeast Asia, Tectonophysics, 482, 92-104, 2010.

Van Kekem, A., Pullens, J. H. M., and Khan, Z.: Soils of the Rainforest in Central Guyana, Tropenbos-Guyana Series 2. Tropenbos-Guyana, Georgetown, Guyana, 1997.

Webb, L.: Cyclones as an ecological factor in tropical lowland rainforest, North Queensland, Aust. J. Bot., 6, 220-228, 1958.

Wilcke, W., Oelmann, Y., Schmitt, A., Valarezo, C., Zech, W., and Horneier, J.: Soil properties and tree growth along an altitudinal transect in Ecuadorian tropical montane forest, J. Plant Nutr. Soil Sci., 171, 220-230, 2008.

Woodward, F. I.: The lowland-to-upland transition-modelling plant responses to environmental change, Ecol. Appl., 3, 404-408, 1993.

Yamakura, T., Hagihara, A., Sukardjo, S., and Ogawa, H.: Aboveground biomass of tropical rain forest stands in Indonesian Borneo, Plant Ecol., 68, 71-82, 1986.

Yoda, K., Kira, T., Ogawa, H., and Hozumi, K.: Self-thinning in overcrowded pure stands under cultivated and natural conditions (Intraspecific competition among higher plants XI), J. Inst. Polytechn., Osaka City University, Ser. D, 14, 107-129, 1963.

Zotz, G., Tyree, M. T., Patino, S., and Carlton, M. R.: Hydraulic architecture and water use of selected species from a lower montane forest in Panama, Trees-Struct. Funct., 12, 302-309, 1998. 